\title{
"EL NIDO DEL ARARA, POSADA PARA MIGRANTES DEL MUNDO": ESTUDIO DE CASO EN ETNOZOOLOGÍA URBANA EN LA CIUDAD DE POPAYÁN (CAUCA, COLOMBIA)
}

\author{
"EL NIDO DEL ARARA (MACAW'S NEST), POSED FOR MIGRANTS FROM THE \\ WORLD": CASE STUDY IN URBAN ETHNOZOOLOGY IN THE CITY OF POPAYÁN \\ (CAUCA, COLOMBIA)
}

\author{
Luis Eduardo BARRAGÁN LEÓN ${ }^{1}$; Eraldo Medeiros COSTA NETO²; Olga Lucia SANABRIA³
}

${ }^{1}$ Programa de Geografía del Desarrollo Regional y Ambiental, Universidad del Cauca (Colombia), e-mail: eduardobarragan@unicauca.edu.co; ${ }^{2}$ Programa de Posgrado en Ecología y Evolución, Universidad Estatal de Feira de Santana, Feira de Santana, Bahía, Brasil, e-mail: eraldont@ @otmail.com; ${ }^{3}$ Universidad del Cauca, Doctorado en Etnobiología y Estudios Bioculturales

\section{RESUMEN}

Submitted: 03/03/2020; Accepted: 27/04/2020

Las evidencias en torno a la relación de los seres humanos y los animales se remontan a milenios. Evidencias que se hallan en diversidad de contextos, como relieves kársticos, cavernas e hipogeos. En estos hallazgos encontramos representaciones iconográficas, plasmadas a partir de petroglifos, pictogramas y en piezas cerámicas. Narrativas gráficas que permiten evidenciar los relacionamientos sociales, culturales y mágicos de los sujetos humanos en relación con la naturaleza. Vínculo que demuestra la trascendencia de la imagen faunística utilizada como símbolo comunicativo. Hoy, se puede observar en la ciudad de Popayán (Cauca, Colombia) la importancia de la imagen faunística en los eventos sociales comunicativos. Una propuesta aplicada en los diversos medios de comunicación audiovisual tanto en espacios físicos, como en plataformas on-line o canales de televisión. En este sentido, se muestra como el enfoque de la publicidad comercial permea el arte popular (muralismo), así como el grado de aceptación de la imagen faunística en los espacios urbanos. Se registran los espacios y contextos de aparición y se propone una revisión de los elementos zoosemióticos en la publicidad, comprendiendo así que la imagen faunística asume gran parte de la carga comunicativa, más allá del texto. El método utilizado para evidenciar la implementación de la imagen faunística en la ciudad de Popayán fue a partir del concepto de cacería urbana, poniendo en práctica un registro fotográfico, que recolecta imágenes etnozoológicas en pendones, afiches, murales, etc. Los resultados obtenidos arrojan 50 fotografías de 22 animales distintos. El desarrollo de este estudio de caso permite percibir los alcances de la zoosemiosis aplicada en la publicidad urbana, en torno a las dinámicas comunicativas. Por último, se propone una hipótesis a partir de los resultados, enfocada hacia los procesos pedagógicos de aprendizaje, que posibilitan el empoderamiento de los grupos poblacionales frente a los procesos de conservación de la fauna en vía de extinción.

Palabras-clave: zoosemiosis; etnozoología; cacería urbana; educación ambiental; Departamento del Cauca.

\section{ABSTRACT}

The evidences around the relationship between human beings and animals go back thousands of years. Evidences can be found in a diversity of contexts, such as karst reliefs, caverns and hypogeum. In these findings we perceive iconographic representations, depicted from petroglyphs, pictograms, and ceramic pieces, which are graphic narratives that reveal the social, cultural, and magical relationships of people in relation to nature. Such a link demonstrates the transcendence of the wildlife image when used as a communicative symbol. Today, the imaginary-symbolic use of animals, both real and stylized, can be observed in various communicative social events. In this sense, this article shows how the commercial advertising approach permeates popular art (muralism), as well as the degree of acceptance of the fauna image in urban spaces in the city of Popayán (Cauca, Colombia). Spaces and contexts of appearance are recorded and a review of zoosemiotic elements in advertising is proposed, thus understanding that animal images assume a large part of the communicative burden, beyond the text. The method used to demonstrate the implementation of the fauna image in the city of Popayán was based on the concept of urban hunting, putting into practice a photographic record, which collects ethnozoological images on banners, posters, murals, etc. The results show 50 photographs of 22 different animals. The development of this case study allowed us to perceive the scope of zoosemiosis applied in urban advertising around communicative dynamics. A hypothesis focused on the pedagogical learning processes is proposed, which enables the empowerment of population groups in relation to the conservation processes of endangered fauna.

Keywords: Zoosemiosis; ethnozoology; urban hunting; environmental education; Cauca Department. 


\section{INTRODUCCIÓN}

El imaginario de la naturaleza ha venido siendo cambiado y reinterpretado por los humanos a través del tiempo, los múltiples fenómenos culturales, sociales, económicos han cumplido una función primordial en esa relación naturaleza-sociedad, algunos de estos con tal incidencia como la idea de cosificación de la naturaleza al igual que naturalización de las acciones de intervención al medio natural por servicios eco-sistémicos, lo que resalta a la vista, uno con mayor fuerza (Ulloa, 2002).

El modelo de consumo capitalista y globalizante que ha avanzado a tal escala que gran parte de la población se ha desplazado a las ciudades (Cotos et al., 2010). Esa migración interna de los países presenta la tendencia contemporánea a apartarnos cada vez más de la realidad rural, lo natural del mercado, y el acceso a productos derivados de los servicios eco-sistémicos locales o externos. Presentan una realidad ambiental apartada y abstracta, que conduce a la humanidad cada vez más a esa pérdida de la memoria, usos y costumbres, a la par del deterioro de la naturaleza a un ritmo acelerado (Hernández, 2017).

Se puede medir la concepción de la naturaleza en las ciudades por medio de la semiótica (Halliday, 1978). Según Marques (2002), "el enfoque semiótico supone que la red culturalinformativa está entrelazada no solo por el conocimiento generado por las interacciones directas entre la experiencia humana y los estímulos del entorno, sino también por los sentimientos, creencias y comportamientos humanos". Por ello, la utilización de las imágenes de animales a nivel comercial y cultural permite un panorama de la relación ser humano-fauna. Teniendo en cuenta que los animales (reales o imaginarios) tienen una fuerte influencia en el imaginario de los seres humanos, a menudo se asocian con productos, negocios y servicios, en un intento de atraer una audiencia más amplia para estos mismos bienes y servicios (Buckley y Araújo, 1997; Marques y Andrade, 1998; Costa Neto, 2000, 2004). Soulé (1997) afirma que los comerciales están diseñados para instigar e invocar emociones y deseos agradables. Más precisamente, evitan los centros cognitivos, comunicándose a través de nuestros deseos físicos básicos (orales, sexuales) y nuestras necesidades emocionales, como la seguridad, la posición social, el control y las ganancias potenciales. Las interpretaciones zoosemióticas resultan, entonces, en estrategias que responden al modelo de consumo como un medio de utilización de la imagen del animal para alcanzar los objetivos del mercado, influenciando la toma de decisiones de las personas (Marques y Andrade, 1998).

La publicidad zoológica urbana que observamos a diario no es un grupo de elementos sueltos que están puestos de manera no intencional; su estructura, forma, tamaño, color, imagen y lugar de ubicación están pensados más allá de lo contemplativo (Vidales, 2009; Souza et al., 2015). Están allí con la finalidad de direccionar, indicar y persuadir el actuar de los grupos expuestos a estas imágenes, a estos signos. Determinando, en cierta forma, el interés frente a la satisfacción de sus necesidades, logrando crear referentes que, como concepto, navegan por diversos medios comunicativos (Vidales, 2009). Futterleib y Azevedo (2013, p. 1) hacen explícito que

La publicidad y la propaganda, como herramientas del proceso de comunicación social, a su vez, no podían ignorar esta rica colección de contenido simbólico en su trabajo técnico. Por lo tanto, hay innumerables piezas y estrategias que utilizan la figura del animal en su proceso persuasivo. Marcas como Vokswagen, Coca-Cola, Dove, Peugeot, NET, Gillette y VISA, usan o han usado animales en sus campañas. Las marcas de automóviles, como Puma, Ferrari y Lamborghini, a su vez, hacen uso histórico de asociaciones con animales fuertes y / o rápidos como felinos, toros y caballos para agregar valor y conceptos y así obtener ventajas para llegar a sus consumidores.

El uso y la funcionalidad de los signos zoológicos en el contexto urbano se pueden observar a través de breves incursiones en las áreas comerciales, industriales y residenciales de la ciudad, además en la publicidad y el arte popular gráfico (mural). Información que presenta la fauna como un elemento principal en sus infografías, aumentando exponencialmente la inclusión de imágenes de animales. Esto, en razón o con relación a la zoosemiosis, de donde se han tomado elementos a partir de las señales emitidas (p. ej., expresiones, funciones, comportamientos) por ciertas especies en sus procesos de comunicación (Saussure, 1969). Señales que son interpretadas de forma colectiva y de las cuales se demuestra su aceptación o rechazo, dando una explicación frente al uso de la imagen 
faunística en la publicidad comercial de la ciudad. Animales que por sus relacionamientos a través de la historia con los humanos han marcado un concepto, y más allá una iconografía popular.

Los fenómenos e interpretaciones alrededor del signo (imagen o caricatura de un dado animal) permiten hacer una lectura de la publicidad, al observar la especie animal representada (Sebeok et al., 1978). Los resultados de las reflexiones aplicadas a las manifestaciones zoosemióticas han resultado en una variedad de signos que definen parámetros para la explotación de la imagen faunística, en la publicidad, como la raza, el color o el comportamiento que se nota entre los animales mismos. De hecho, la comunicación entre especies animales es maravillosa. Se observa que para buscar el alimento, reproducirse y sobrevivir, establecen relaciones de grupo, al interior del cual se asocian y comparten, logrando comunicación a través de vocalizaciones, como gritos, cantos, silbos, graznidos, y a través de distintos movimientos y ceremonias rituales (Araújo et al., 2005; Niño, 2013; GalvagneLoss, 2013). A estas señales, como elementos de la comunicación entre especies, les debemos las interpretaciones colectivas de nivel perceptual, lo que posibilita la comprensión de mensajes subliminales. Este descubrimiento permite persuadir y aportar al mercado a través de la publicidad de masas. Sonidos, colores, formas, el cine, la TV, la llegada del internet potencializan el uso de la imagen zoológica a favor del modelo de consumo, direccionando el imaginario de la Naturaleza y nuestra relación con ella (Vidales, 2009).

Parte fundamental de este artículo es presentar la interacción del ser humano con los animales por medio de los signos, al igual que su finalidad. De esta manera, se adelanta una revisión de signos convencionales zoológicos presentes en diferentes contextos de la ciudad de Popayán, Departamento del Cauca, Colombia. Rastreando la existencia de la semiosis en este contexto urbano, revisando la triada de Charles Morris con línea de base semiótica, un proceso que se presupone al menos por tres factores: 1) lo que actúa como signo (el vehículo); 2) aquello que el signo hace referencia (el designado); y 3) el efecto sobre un intérprete. Por el cual el objeto en cuestión se convierte en signo por el intérprete (el interpretante). El concepto de "intérprete" es un cuarto factor que permite explicar el proceso semiótico mediante la aserción de que un signo se refiere a algo para alguien (Morris, 1938).

Un elemento principal para comprender la semiótica desde la óptica de Morris (1971), quien remonta la doctrina de Peirce, es la definición de pragmática implícita en este estudio de caso en etnozoología urbana: para caracterizar con precisión la pragmática bastara con decir que se ocupa de los aspectos bióticos de la semiótica, es decir, de todos los fenómenos psicológicos, biológicos y sociológicos que se muestran en el funcionamiento de los signos (Morris, 1971).

Dimensionar la influencia que ejerce la imagen zoológica en el paisaje urbano, y al vincularla con la educación ambiental, se puede llegar a jugar un papel fundamental para el desarrollo de planes, programas y proyectos que logren acertar en la conservación de la biodiversidad (Myers et al., 2000). Y más aún en las especies en vía de extinción, o con un alto grado de vulnerabilidad. La utilización de estos elementos publicitarios en la labor de resignificar el quehacer de la educación ambiental, facilitando la comprensión en cuanto al concepto conservación, e incluyendo procesos educativos participativos que apunten hacia la generación de una conciencia ambiental vista desde la ciudad.

Llegando a esto por medio de adentrarnos en la influencia publicitaria etnozoológica a través de ejercicios propios de la investigación acción participante de Rahman y Fals Borda (1992), que permitan a sus planificadores educativos proponer acercamientos en contexto, ajustes en sus planes de acción en cuento a la educación ambiental su enfoque y la concertación con los actores sociales para una divulgación coherente en contexto, en vías de una educación ambiental popular. Llevándonos a cuestionarnos en cuanto a: ¿Es posible implementar la imagen zoológica publicitada en la urbe, como una herramienta en la educación ambiental para la sustentabilidad, que apunte a la identificación y conservación de la fauna en la ciudad de Popayán en vía de extinción?

\section{MATERIAL Y MÉTODOS}

Este estudio en etnozoología urbana se desarrolló al interior de la ciudad de Popayán, capital del Departamento del Cauca, ubicada al oeste de Colombia y al suroeste de la ciudad de Bogotá a una distancia de $596 \mathrm{~km}$. La ciudad fue fundada por el español Sebastián de Belalcázar el 13 de enero de 1537 como capital de la entonces Gobernación del Gran Cauca, evoca su nombre del Cacique Pioyá, antiguo cacique de los Pubenenzes, primeros habitantes de la zona (Alcaldía Municipal de Popayán, 2020). 
Popayán se encuentra a una altitud de 1.738 metros sobre el nivel del mar, con una temperatura media de $19^{\circ} \mathrm{C}$, se localiza en los $2^{\circ} 27^{\prime}$ norte y $76^{\circ} 37^{\prime}$ de longitud oeste del meridiano de Greenwich (Municipio de Popayán, 2000). La población estimada es de 270 mil habitantes aproximadamente en su área urbana. La ciudad es bañada por 11 fuentes hídricas que la atraviesan en diferentes direcciones, trazando y dinamizando la ciudad de diversas maneras, observables en su distribución urbanística, comercial, industrial y por su puesto sus dinámicas culturales (Alcaldía Municipal de Popayán, 2020).

La ciudad disfruta de elementos paisajísticos, como el Volcán Puracé al sur oriente de la ciudad, que puede ser apreciado en las madrugadas de los meses de verano, por su ubicación sobre la falla de romeral que atraviesa el país de sur a norte en la zona andina, y tiene una alta actividad sísmica (Alcaldía Municipal de Popayán, 2020).

Popayán se asienta en dos zonas de vida, el bosque andino y sub andino, por lo que su biodiversidad es bastante amplia. El altiplano de Popayán compone uno de los cinco distritos biogeográficos del departamento, siendo un sitio primordial para la investigación biológica debido a que es una zona en donde confluyen las características de las zonas adyacentes (Zamora, 2000).

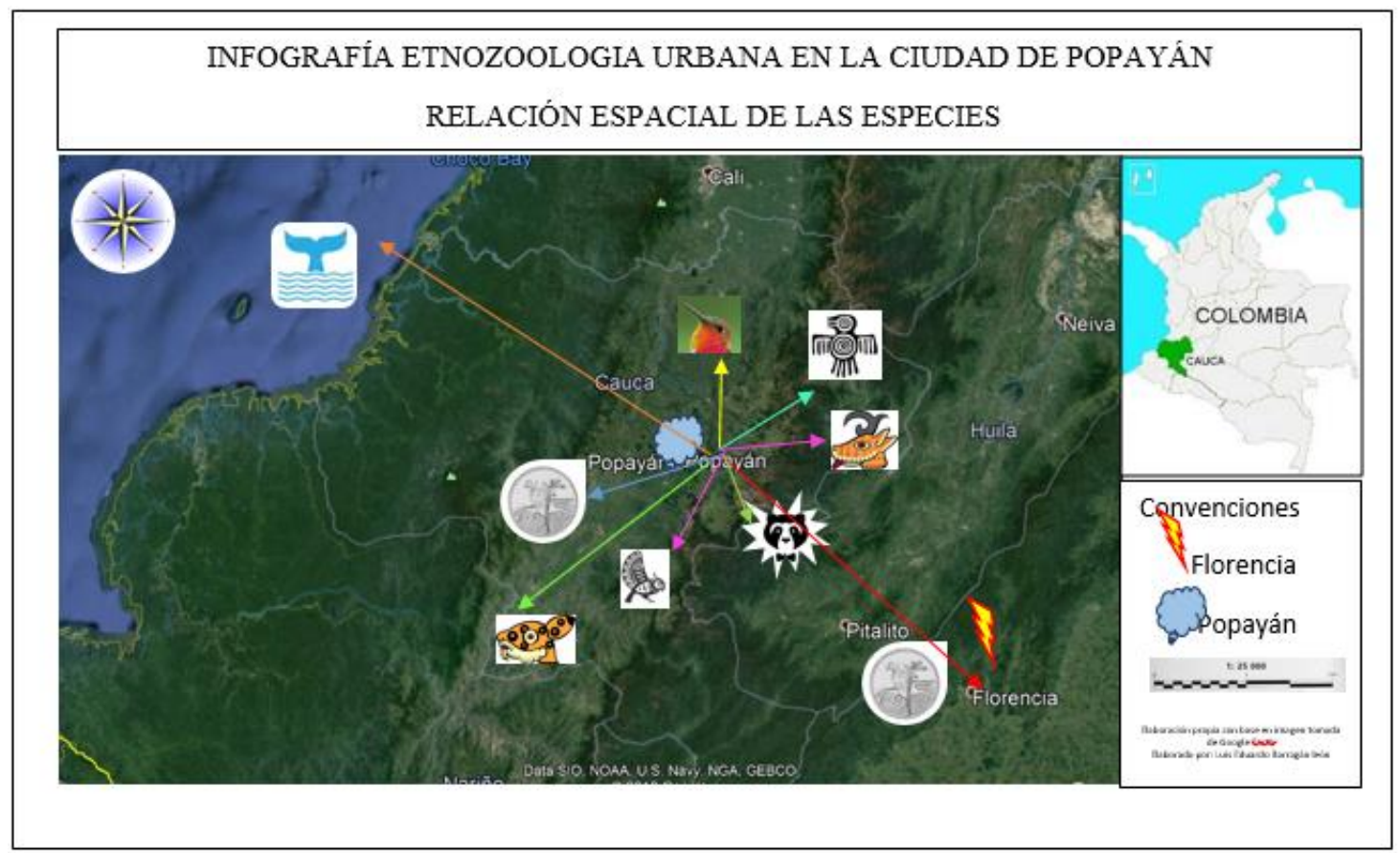

Figura 1. Infografía urbana en la ciudad de Popayán. Relación espacial de las especies. (Fuente: elaboración propia, 2019).

La meseta de Popayán alberga una gran cantidad de aves de variados colores y formas. Al menos 70 especies se pueden observar en el corredor entre Popayán y Timbío. Algunas son migratorias y otras habitan el área. Se registran 60 especies de mamíferos y una gran riqueza en invertebrados. Entre las especies vegetales, las más comunes son el roble (Quercus humboldtii) que se ha convertido en el árbol símbolo de la ciudad, cucharo (Myrsine guianensis), cascarillo (Cinchona pubescens) y de unos años para acá los guayacanes amarillos (Tabebuia chrysanta) y lilas (T. rosea) le han dado identidad a las principales calles y avenidas de la ciudad (Alcaldía Municipal de Popayán, 2020; Vargas Garzón y Molina Prieto, 2008).

\section{Colecta de datos}

Para el desarrollo de este estudio de caso, se propone una primera actividad denominada cacería urbana, ya que se puede encontrar una diversidad de animales plasmados en el ecosistema urbano (Costa Neto, 2004). Proceso a través del cual se obtuvieron las imágenes relacionadas con este estudio en etnozoología urbana. Imágenes que permitieran, desde un principio, plantearse una idea de la interpretación de la fauna en la urbe y los elementos de comunicación que rodean estas interpretaciones iconográficas. 
La actividad de campo se desarrolló entre el 20 de octubre al 30 de noviembre del 2019 al interior de los barrios La Esmeralda, El Bolívar y El Centro, además del interior de la Universidad del Cauca. Cacería urbana que se logró a través de la captura de imágenes por medio de un equipo fotográfico y auditivo Blackview V 6000 ip 68, al igual que con un programa que permitió trazar la ruta de la "cacería". Las fotografías están mantenidas con el primer autor.

En este orden de ideas, se recorre cuadra por cuadra, de las zonas comerciales e industriales, de la ciudad, en busca de imágenes de fauna incluidas en la publicidad comercial, murales, afiches, pendones, entre otros, sin dejar de lado el ejercicio de observación participante por medio del cual nos permitiera tener un acercamiento con las personas en cada uno de los contextos. Si bien hubo fotografías en las cuales no se pudo indagar sobre su instalación, en la mayoría de los casos se logró hablar con los propietarios de la publicidad al igual. También fue posible establecer relación con personas cercanas a las obras pictóricas tipo mural, con el fin de ahondar en el sentir frente a la existencia de tales iconografías, además del porqué del uso de animales en las imágenes publicitarias, lo que se describirá con detalle a continuación.

\section{RESULTADOS Y DISCUSIÓN Cacería urbana en Popayán}

Los resultados obtenidos arrojan 50 fotografías de 31 animales distintos, que se distribuyen en los siguientes grupos taxonómicos: mamíferos (14), aves (7), insectos (6), arácnidos (1), peces (2) y reptiles (1). Lo que permitió identificar el mundo animal en las expresiones urbanas de forma tangible al interior del comercio local, abriendo camino a múltiples interpretaciones que se condensan en este artículo.

Las imágenes faunísticas, la obra pictórica o el arte popular (mural), al igual que los involucrados que se lograron registrar a través de este proceso, ofrecen una lectura del comportamiento social. Esto, después de ordenar los elementos del medio ambiente urbano, por medio de los símbolos de las iconografías plasmadas en la publicidad o el espacio público que lo contiene. Además de conocer el significado para la cultura local. Dar respuesta a si las imágenes están allí por decisión, tendencia o casualidad es una de las inquietudes que enmarca este estudio de caso. Como resultado, se puede evidenciar un dominio publicitario tradicional, entendiendo como "tradicional" la publicidad que utiliza el texto y los colores, más que las imágenes en ella.

La ciudad de Popayán, vista desde tres barrios como lo son La Esmeralda, El Bolívar y El Centro, no presenta un alto grado de inclusión de la imagen faunística en sus elementos publicitarios. Podría definirse una nueva tendencia de diseño, donde las fuentes y los colores acompañados de nombres, preferiblemente en otros idiomas, han dominado la publicidad de la ciudad. Al inicio de este estudio, a partir del enfoque en etnozoología urbana, y el concepto de cacería urbana, se visualiza un escenario de cacería, de safari, o bien, como una acción frente a la búsqueda y rastreo de animales (Costa Neto, 2004). Lo cual deja a la vista la mínima inclusión de la imagen faunística en la ciudad. Aspecto que podría darnos una lectura de la realidad social frente al reconociendo de las especies faunísticas en vía de extinción, su apropiación frente al desarrollo de actividades de protección y conservación. Tras este recorrido de cacería urbana, y al evidenciar la carente utilización de imágenes faunísticas en la publicidad comercial de la ciudad vista desde estos tres barrios, se da paso a intensificar el rastreo y ampliar la búsqueda a la periferia de los sectores nombrados, dado que en la zona de galerías, plaza de mercado, almacenes de distribución de comida y bodegas, no se evidenciaba el uso de la imagen faunística.

El registro de datos toma forma y direcciona el estudio a partir de un hallazgo representativo, que da pie a la demostración y discusión de las formas en que se lleva a cabo la instalación de murales de arte popular en la ciudad. Esto, por medio de una institución educativa pública de educación básica primaria y secundaria, la cual en sus paredes externas, de dimensión mayor a 50 metros lineales, muestra una serie de murales, en los cuales hallamos al cóndor (Vultur gryphus), el tigre (Panthera onca), la guacamaya (Ara chloropterus), el puma (Puma concolor), el colibrí (Trochilidae) y algunos peces animados. Tal mural en específico fue generador de inquietudes para el investigador (primer autor), quien, al observar una institución educativa rodeada de estas representaciones gráficas de la fauna propia de la región, centró su atención en la intencionalidad implícita de su elaboración. Para no dar paso a especulaciones sin sentido, se hizo una revisión al caso por medio del proceso de observación participante, logrando un acercamiento con el rector del colegio, para resolver la duda 
respecto a si estos murales hacen parte de un plan de trabajo concertado con la institución educativa y la comunidad en general, al igual del porqué de la escogencia de estos símbolos.

Los resultados de esta conversación evidencian procesos contrarios a la unificación de esfuerzos, apropiación y realización de actividades que propendan por la ejecución participativa de actividades dentro del marco de las artes populares como lo es el muralismo, proceso vinculante de elementos académicos de identificación, conservación y protección de la fauna en vía de extinción. Lo que se demuestra son procesos al azar que no coinciden con los proyectos de la institución y de los cuales sus docentes no se apropian, dejando de lado este medio iconográfico artístico.

El rector de la institución académica afirma que este trabajo de muralismo en lo único y para lo único que se incluyó a la institución, fue para la autorización del uso de la pared; que de por si, por ser una institución pública y estar ubicada al interior de un barrio, cuenta con una junta de acción comunal, ente regulador que tiene participación en las decisiones sobre el espacio público, actuando sobre la decisión de instalar el mural. El cual fue liderado por un grupo externo que no propuso una articulación para su desarrollo. A la luz, salió un elemento clave resultado de esta conversación. Al cuestionar al rector sobre la reacción comunitaria frente a la instalación de esta obra pictórica (mural), él menciona que uno de los problemas más notorios que se presentaban antes de la instalación del mural esta zona era el problema de las basuras que tiraban en el espacio público y los andenes que rodean la zona comercial del barrio La Esmeralda. Según su testimonio, después de que se pintó el mural, disminuyó en gran medida el arrojamiento de basuras en el sector. Lo que a su vez indica un posible control sobre el manejo y disposición de las basuras, mostrando que este tipo de imágenes se convierten en un símbolo frente a la "apropiación del espacio público", según palabras del rector.

Como un último elemento de este acercamiento comunitario de diagnóstico, se cuestiona al rector sobre si estos trabajos artísticos iconográficos podrían pasar a ser una herramienta pedagógica frente a la conservación de la fauna. En este sentido, aclara el rector que el límite presupuestal es lo que impide el desarrollo de este tipo de procesos vinculantes entre sectores.

El acercamiento con estos murales etnozoológicos y con esta institución educativa afianza la hipótesis del investigador, que propone un trabajo de identificación, conservación y protección de la fauna por medio de las representaciones gráficas urbanas etnozoológicas, incluidas como ruta y plan de estudio de la básica primaria y secundaria.

El recorrido por la ciudad cuadra por cuadra permitió observar el nivel de apropiación de la imagen y sobre todo, se logró notar como los procesos específicos de muralismo carecen de acuerdo de voluntades donde las comunidades sean partícipes. Donde se encamine a una apropiación de la imagen y quizás más allá, a concertar en la construcción de significados colectivos, como aportes comunitarios implícitos en el desarrollo de estos ejercicios muralistas. Efectuando así, una producción colectiva que precise el sentido comunitario (Cajiao, 2004).

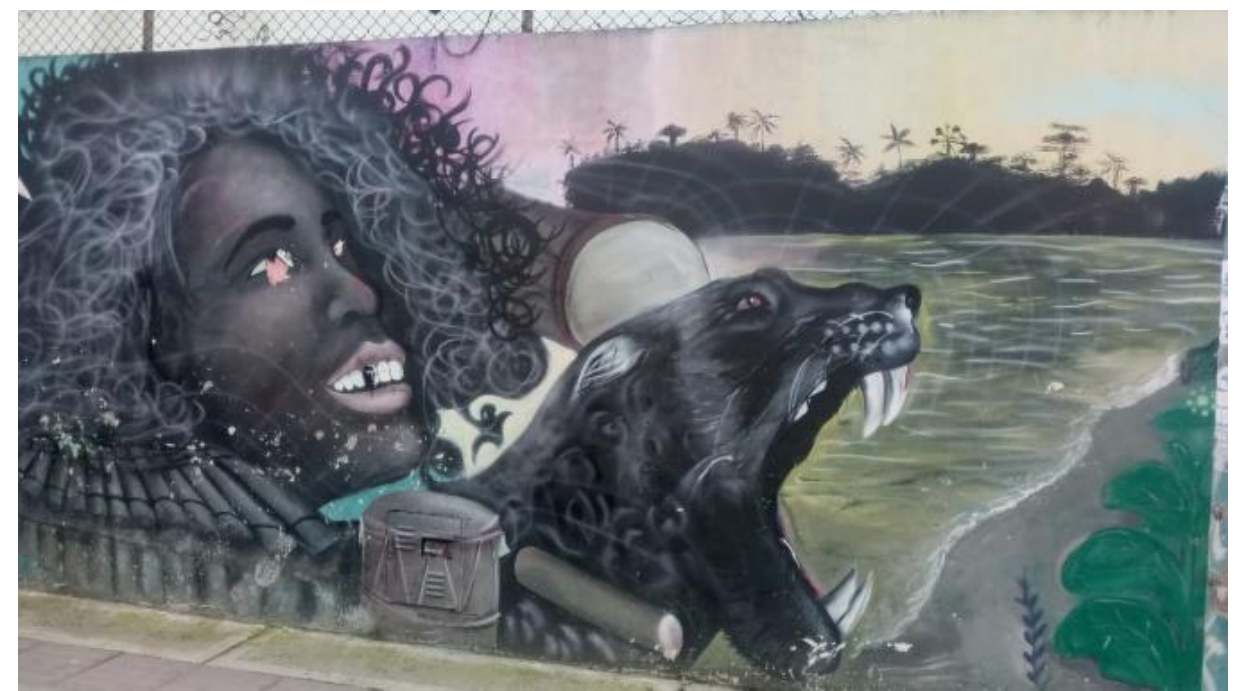

Figura 2. Puma (Puma concolor) en las Costas del Pacifico. Mural de la Institución Educativa. (Fuente: Luis Eduardo Barragán, 2019). 


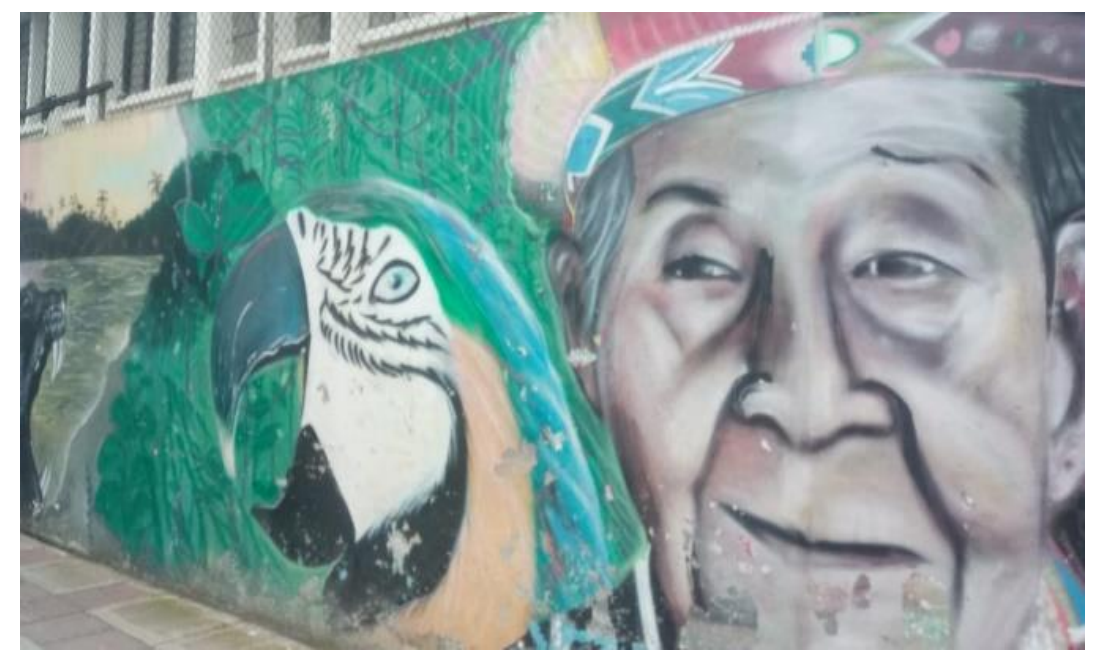

Figura 3. Curaca y Arara (Psittacidae) en la Amazonía. Mural de la Institución Educativa. (Fuente: Luis Eduardo Barragán, 2019).

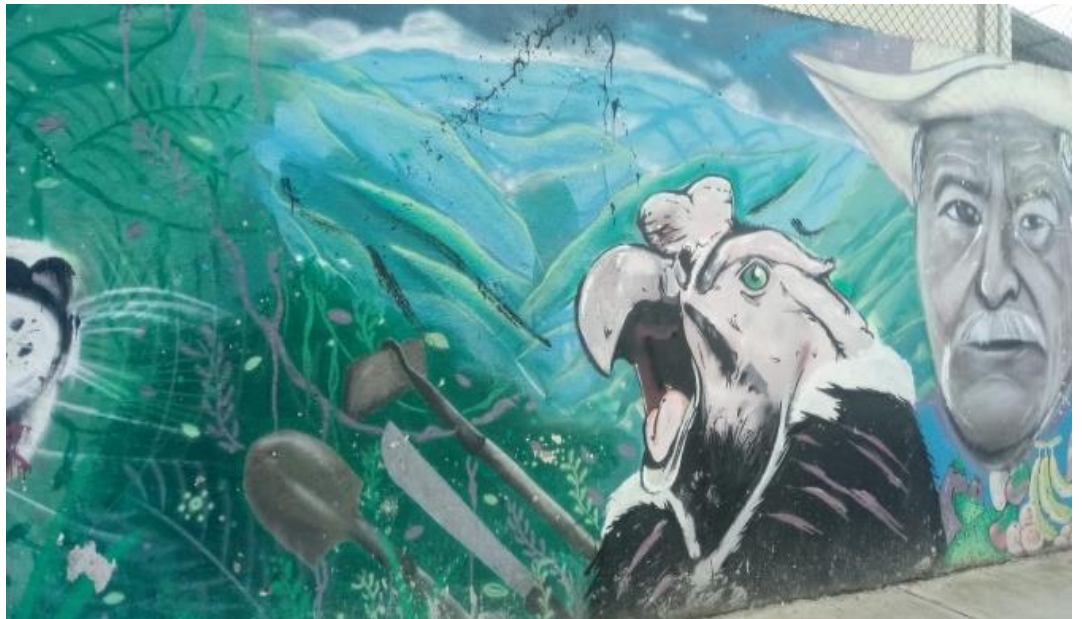

Figura 4. Cóndor (Vultur gryphus) en el contexto campesino. Mural de la Institución Educativa. (Fuente: Luis Eduardo Barragán, 2019).

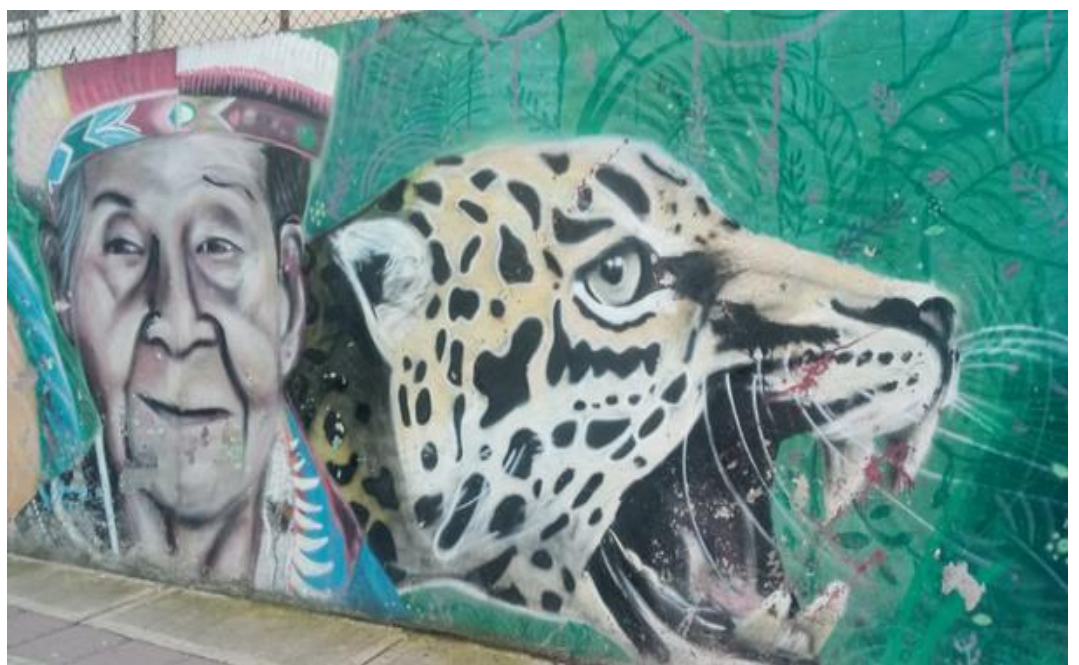

Figura 5. Curaca y Jaguar (Panthera onca). Mural de la Institución Educativa. (Fuente: Luis Eduardo Barragán, 2019). 


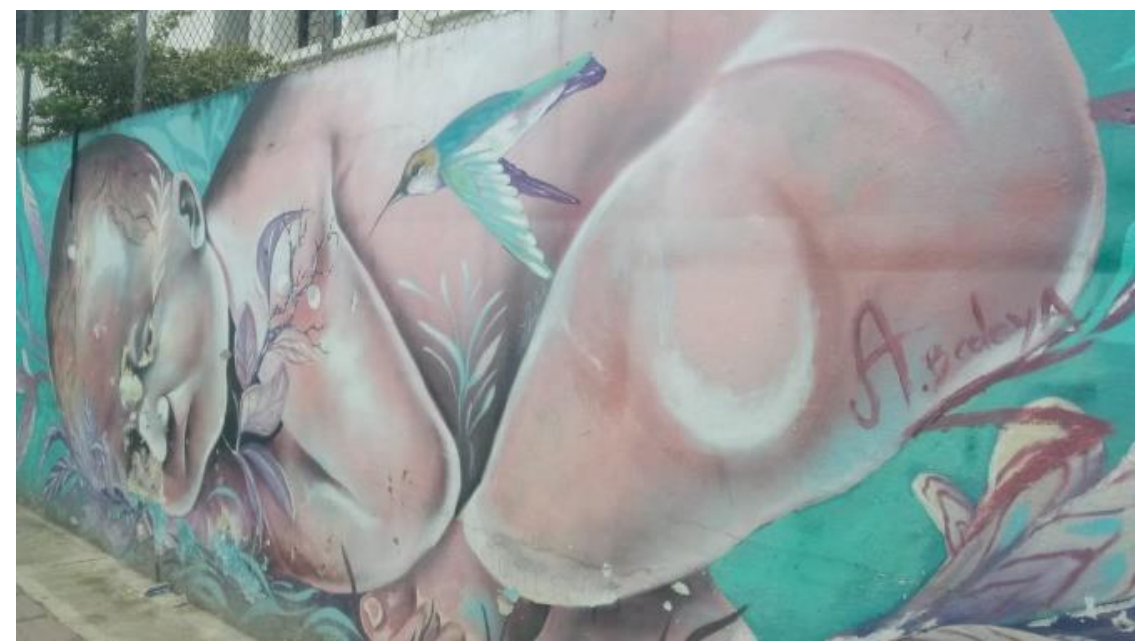

Figura 6. Nacimiento y colibrí (Trochilidae). Mural de la Institución Educativa. (Fuente: Luis Eduardo Barragán, 2019).

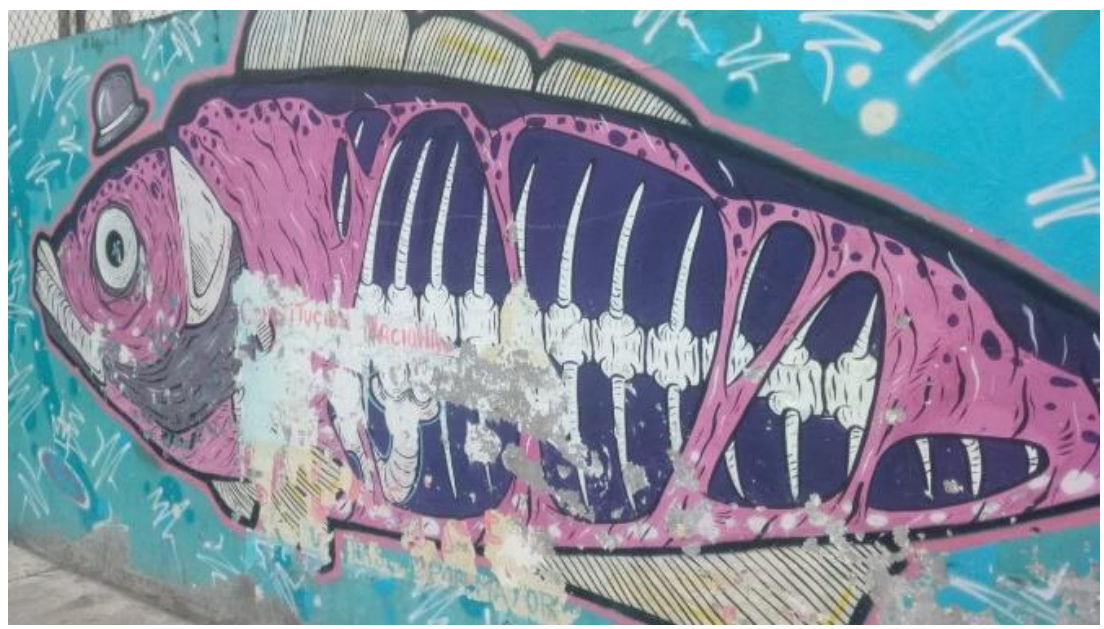

Figura 7. Pez animado. Mural de la Institución Educativa. (Fuente: Luis Eduardo Barragán, 2019).

Como bien lo plantea Francisco Cajiao en su artículo "La concertación de la educación en Colombia", podemos observar en cuanto a las decisiones estatales en educación no han pasado de ser una propuesta estatal que luego se opaca por las contrarreformas que han caracterizado al gobierno nacional; poner en la mesa supuestas acciones que se enmarcan en las políticas mundiales es un ejemplo claro de lo ocurrido a partir de los años noventa con la asamblea nacional constituyente, influida por las corrientes internacionales y las declaraciones en las cumbres mundiales de educación, donde se replantea la participación social en las tomas de decisiones en cuanto a la educación (Cajiao, 2004).

Lo anterior es un ejemplo claro de lo que vienen ocurriendo a nivel nacional, permitiéndonos aclarar el porqué de que las acciones barriales en cuanto a la puesta en escena de propuestas gráficas muralistas no coincidan con procesos participativos, siendo este reflejo de una política estatal que permea las acciones barriales y comunitarias, se está accionando sin concertación comunitaria, proceso que aparta a la educación ambiental cada vez más de los programas en educación ambiental de las instituciones educativas y por supuesto, de los proyectos comunitarios en educación ambiental (PROCEDA). Dejando a unos pocos la implementación de propuestas que pueden llegar a ser las bases de la educación ambiental para sustentabilidad (Alvarado Corredor y Gualteros Blanco, 2016).

\section{Los signos etnozoológicos como vehículos de cambios}

Como lo plantea Charles Morris, deberíamos de concertar ese vehículo sígnico, ese objeto o estimulo sensorial, de tal manera que haya una apropiación de los signos, en lugar de dejarlos a la decisión de unos pocos (Morris, 1927). El espacio público está cargado de signos que expresan, representan y comunican algo a alguien, que indistintamente de la relevancia del contenido en la construcción de sí mismo, cumple un papel significante en el contexto en que se encuentra (Sebeok et al., 1978). Por otro lado, existen casos de habitantes que no le dan sentido a las señales, o 
sorprendentemente, han estado muy cerca de los signos y en el momento en que los perciben por primera vez, los detallan detenidamente y los cuestionan, les produce un ruido cognitivo. Es decir, los signos estaban invisibilizados (Clapp et al., 2018).

Una sociedad con cada vez más problemas de comunicación distante de las relaciones personales, podría tomar elementos de la etnozoología urbana para mejorar la comunicación entre sus habitantes. De tal forma que se concertar la interpretación de la ciudad y se comunique por medio de símbolos que van más allá de la imposición de significados y direccionamientos colectivos, y así, constituir una comunicación más humanística y menos permeada de los intereses del modelo de consumo. Además, las artes han sido y seguirán siendo un elemento de comunicación que articula y teje elementos que logran producir un sentido más allá de lo estético, orientando el sentir en relación a la importancia de la implementación de expresiones artísticas visuales colectivas, en torno a las infografías que nos rodean.

La imagen faunística y su asociación con la diversidad de servicios y productos comerciales son notorias en la ciudad de Popayán, aunque en menor proporción. No obstante, la inclusión de la imagen faunística en la publicidad no es al azar, ya que son evidentes las relaciones existentes entre el producto y las especies, así como su intencionalidad. Las señales zoosemióticas son avances de tal nivel de arraigo que han venido siendo una estrategia de persuasión que cada día logra más avances significativos.

\section{Los signos zooculturales hallados en Popayán}

Dando continuidad a esta reflexión en torno a los signos convencionales zooculturales rastreados en la urbe de la ciudad de Popayán, se presenta una descripción del contexto y la imagen expuesta en el medio publicitado. Esto, tras la identificación de la capacidad de observación y reflexión popular sobre la fauna. Vale aclarar que si bien este trabajo se centra en los análisis desde el investigador (LEBL) más que desde la óptica de visión de los involucrados, para algunos casos se consideró la opinión de los espectadores.

Iniciemos este viaje de cacería urbana desde la especie más distante a nivel geográfico: el búfalo (Bubalus bubalis), una especie introducida en el país, que en las últimas décadas se ha observado su crecimiento e incursión en el mercado de las carnes. La imagen que adoptó un restaurante de carnes presenta al búfalo como símbolo principal de su anuncio publicitario, lo que indica que en ese lugar se puede acceder al consumo de carne de este animal. Tal restaurante se encuentra localizado en la zona Centro de Popayán. La imagen del búfalo no solo permite hacerse una idea clara del servicio que se ofrece, sino que además imprime un elemento innovador en la publicidad de los restaurantes de carne. Valga aclarar qué no es el único plato que se ofrece, pero si es el único restaurante de la zona que presenta a un búfalo para tal fin publicitario. A pesar de la existencia de otros restaurantes de carne con este mismo producto, se limitan al texto y el color para publicitar sus productos, mientras que en este restaurante en particular, la información de los propietarios es concisa y va directamente relacionada a la especie y su oferta de carne de búfalo.

Las imágenes del pollo (Gallus gallus domesticus) en los restaurantes de la ciudad de Popayán abundan. El pollo es presentado de forma animada, cocido o simplemente vivo. Quizá esta imagen del pollo es una de las más utilizadas en la ciudad dado que predominan los almacenes que comercializan esta especie, podemos decir que la ciudad está bajo la influencia del pollo. Y por parte de los consumidores, existe una gran aceptación frente a la especie, pues se han logrado posicionar en el imaginario de la comunidad, la necesidad de incluir el pollo en su dieta alimentaria. Ello, a pesar de los daños que puede causar por su origen y procesos de cría, sin nombrar los desastres ambientales producidos por la cría de esta especie, sus residuos y el trato dado en cautiverio. El incremento en el número de animales y la regionalización de las producciones han generado fuertes presiones sobre los productores de ganado y aves (Chalate-Molina et al., 2010) porque si las operaciones de producción no son manejadas adecuadamente, la descarga de nutrientes (materia orgánica, patógenos y emisión de gases) a través de los desechos pueden causar significativa contaminación del agua y el aire. Todo esto en respuesta a suplir las necesidades del mercado, un mercado inducido. Tanto así que se podrían contar cientos de lugares de expendio de carne de pollo en todas las presentaciones comestibles. 


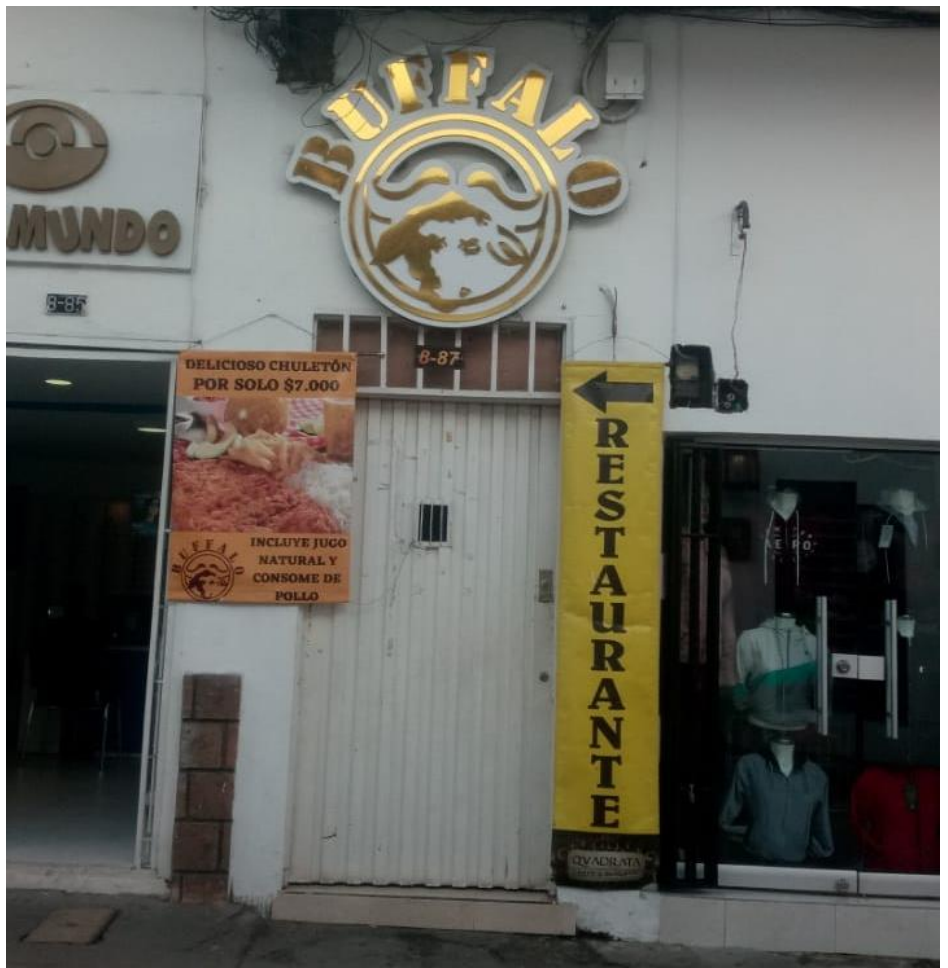

Figura 8. Ícono del búfalo (Bubalus bubalis) en la fachada de un restaurante en la zona El Centro de Popayán. (Fuente: Luis Eduardo Barragán, 2019).

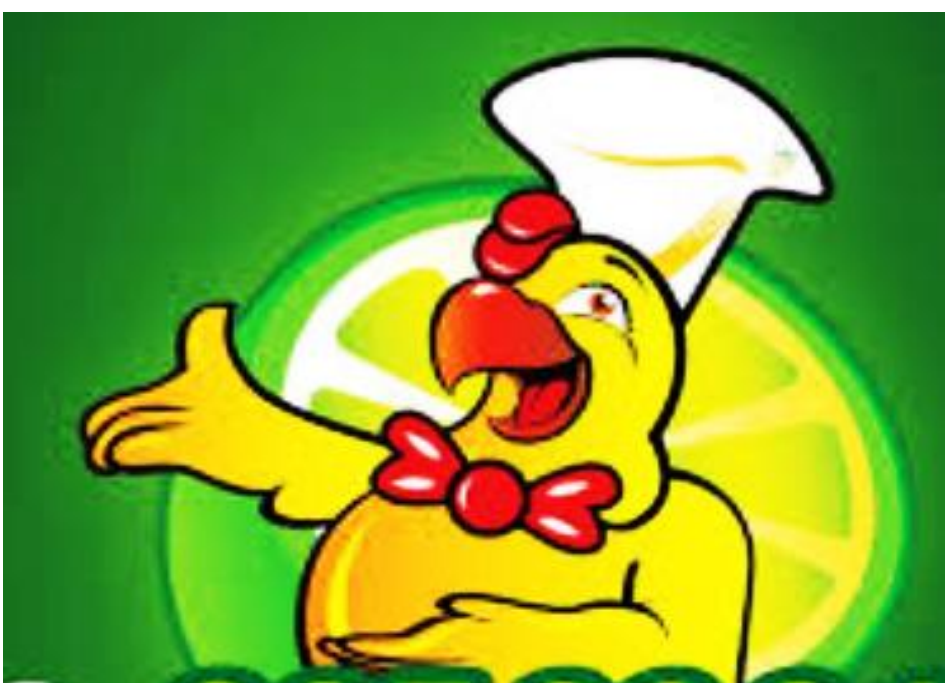

Figura 9. Imagen estilizada de pollo con sabor a limón. (Fuente: Luis Eduardo Barragán, 2019).

Por otra parte, se registra en la zona de distribución de pesca de la plaza de La Esmeralda un mural con dos ballenas jorobadas (Megaptera novaeangliae), una a cada lado de la imagen de una mujer afro-descendiente del pacífico colombiano, adornado por un paisaje de playa y palmeras propias de la zona. A sus dos costados, se hallan dos aves de la misma especie con coronas en su cabeza, el bicho-fue (Pitangus sulphuratus). Estos murales presentan la misma dinámica en su proceso de instalación, son procesos que se concertaron únicamente con las juntas de acción comunal, dentro de un programa de la Alcaldía Municipal de Popayán. El contexto de este mural se encuentra en la zona de la periferia de la plaza de mercado facilitando, de cierta manera, la identificación de la zona de distribución de pescado.

La segunda imagen que se registró es un pez animado que tiene características de varias especies en sí misma. Por su diseño animado, se podría especular que la especie se encuentra como parte del letrero de un almacén de venta de pescado denominado Pesquera Los Delfines.

El uso de estas imágenes facilita la comprensión y búsqueda de los interesados dado que permiten por medio de la imagen arrojar información clara del producto al cual se está direccionado, si bien en este lugar no se encuentran subproductos del delfín, más bien vendría a ser una referente de los 
productos, relacionados con peces de mar, más que de peces de rio, situación contradictoria al revisar qué el mayor porcentaje de especies que allí se redistribuyen son de rio o laguna, como la trucha arcoíris (Oncorhynchus mykiss) criadas en al Cauca, de las zonas frías, especie que a la fecha no se conoce con exactitud los daños ambientales al ecosistema rio, dado que es una especie invasora, rapaz, que por sus características ha aportado a la desaparición de una gran parte de las especies endémicas de los ríos de la parte alta del departamento del Cauca.

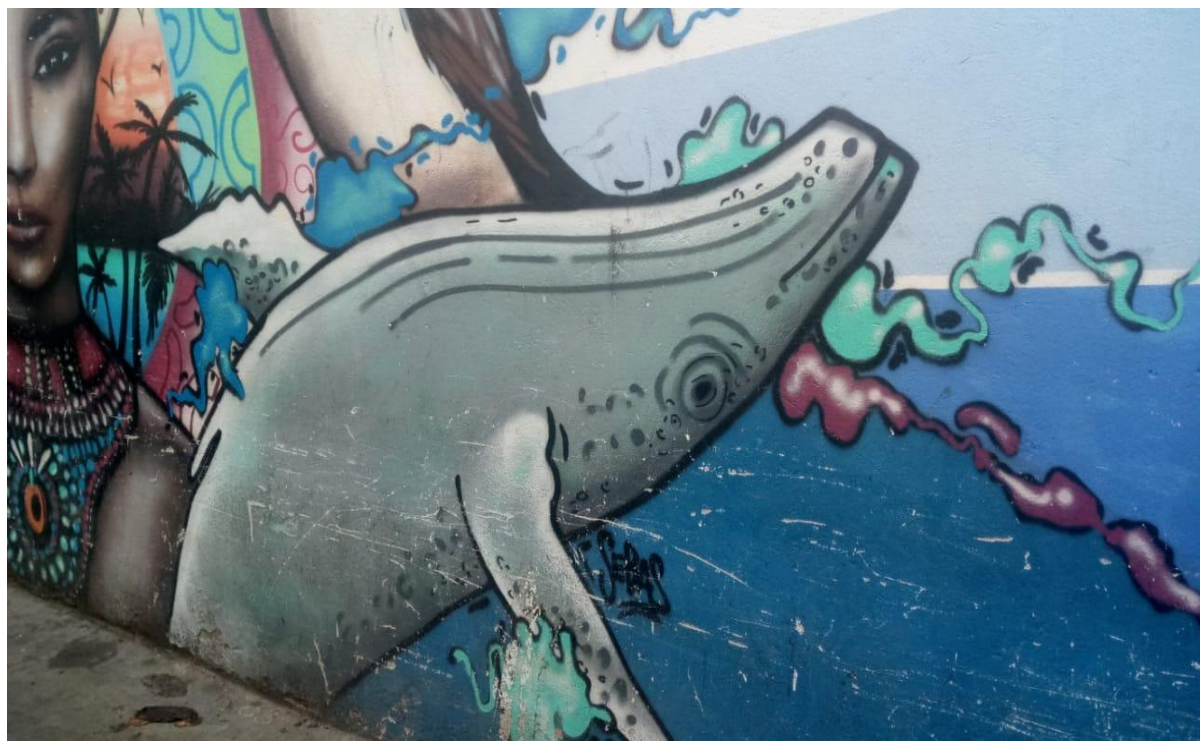

Figura 10. Mural pacifico en zona de pesca con dos imágenes de bi-cho-fue (Pitangus sulphuratus) y dos ballenas Megaptera novaeangliae. (Fuente: Luis Eduardo Barragán, 2019).

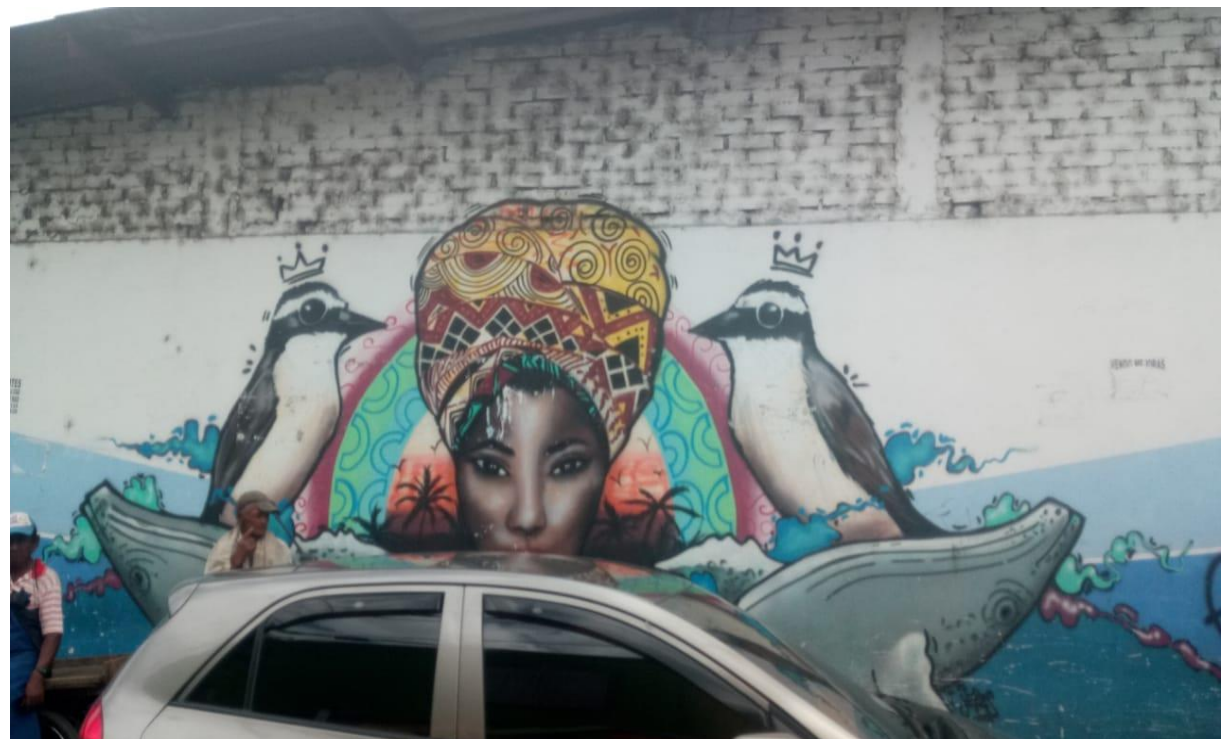

Figura 11. Detalle del mismo mural pacifico donde se presenta la ballena jorobada (Megaptera novaeangliae). (Fuente: Luis Eduardo Barragán, 2019).

De hecho, las especies exóticas introducidas accidental o deliberadamente, también conocidas como especies invasoras, son organismos que se instalan exitosamente en ecosistemas autóctonos (Delariva y Agostinho, 1999). Los efectos causados por estas especies, tales como la alteración del hábitat o la perturbación de los procesos ecosistémicos, constituyen una amenaza grave para las especies nativas y para la estabilidad de los sistemas ambientales afectados (Rodríguez, 2001; Vilá et al., 2008). A pesar de sus grandes afectaciones al ecosistema rio se sigue promoviendo eventos de pesca donde liberan por cientos de estos peces a los ríos de la región del Puracé entre otros para el libre esparcimiento de la población, no se encontraron estudios sobre la afectación de esta especie en la región. 


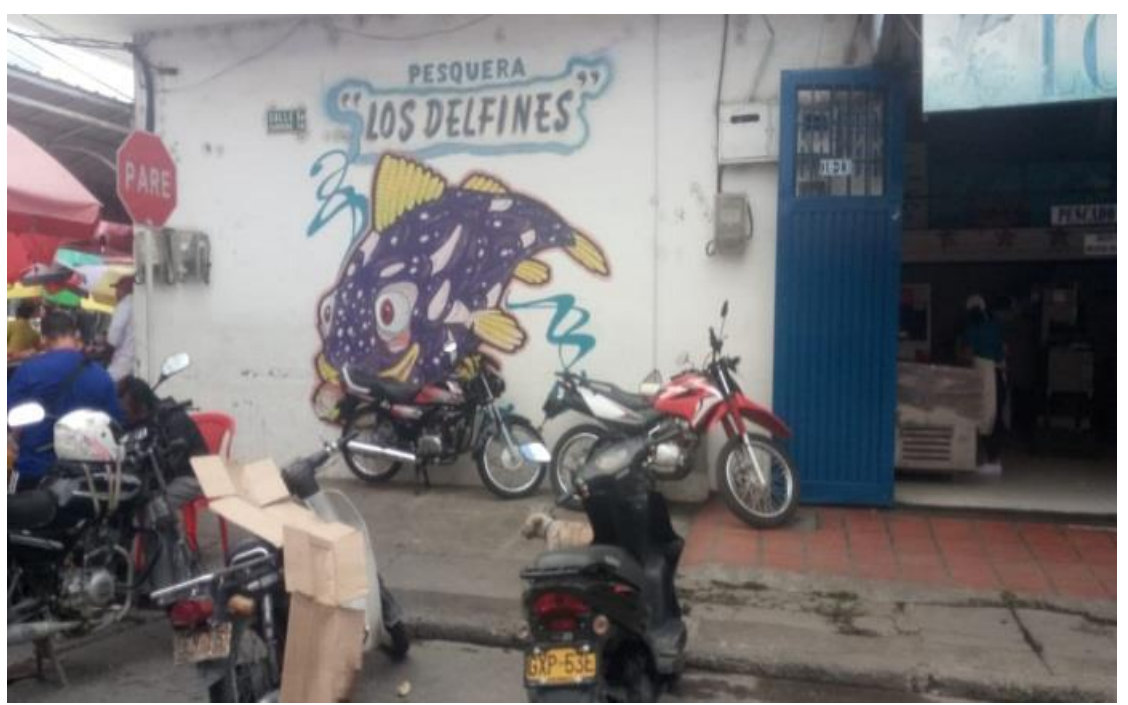

Figura 12. Pez animado en zona de pesca y zoonimia del establecimiento comercial. Plaza de mercado La Esmeralda. (Fuente: Luis Eduardo Barragán, 2019).

Siguiendo con el recorrido de safari con la cacería urbana, se encuentra una representación gráfica a través de un mural, portadora de elementos con una carga simbólica estimulante. Para los autores, al parecer es la figura que reúne y sintetiza la relación humano-fauna en armonía. En ella se puede observar una integralidad simbólica en contexto, lo que permite hacer un recorrido mental por la región, por el Departamento del Cauca, solo con ver el mural. El mural deja a la vista elementos culturales, tradicionales, artesanales y del mismo uso y costumbres alrededor de la relación con las especies. Representa todo un mapa mental en torno a la mujer y su relación intrínseca con la naturaleza, con el ecosistema y a su vez con las especies que allí habitan (se notan un venado, un conejo y dos aves), permitiendo demostrar históricamente la relación sociedad-naturaleza.

Desconocer estas interacciones perceptuales con los animales a nivel cognitivo, simbólico, afectivo, ecológico y económico tiende a invisibilizar la multiplicidad de relaciones vigentes en cuanto a los procesos de deterioro social y de degradación ambiental. Por ello, los procesos comunicativos adelantados por medio de los murales deben de dar paso a la socialización de información crítica y certera que ahonde en la conciencia de un pueblo adormecido por las dinámicas del modelo de consumo, que, a pesar de estar inmerso en la pobreza, sigue convencido de que esta realidad bajo la que se encuentra es una opción de vida (Herrera, 1994).

El safari llega a una de las alturas máximas, a los 5.000 metros sobre el nivel del mar, donde los vientos fríos de Los Andes avistan el cóndor (Vultur gryphus) en medio de las abrumadoras nieblas. Símbolo cultural de Los Andes, que refleja para la ciudad de Popayán lo mismo que el arara o guacamaya para la ciudad de Florencia-Caquetá (Colombia), como veremos al cierre de este estudio de caso. Se podría esperar que este símbolo estuviera en múltiples espacios publicitarios dado su arraigo cultural y su cercanía con el páramo del Puracé, habitat de esta ave. Como tendencia a nivel etnozoológico en la publicidad comercial al interior de la ciudad de Popayán, durante el safari se logró evidenciar un solo cóndor, lo que pareciera coincidir con la realidad particular de desaparición de la especie a nivel local, ya que ha pasado de ser símbolo de conservación a convertirse en una atracción en las inmediaciones del páramo, donde tienen cebado al animal con fines recreativos y turísticos.

El hallazgo del cóndor en la urbe fue en la plaza de mercado de La Esmeralda, en un almacén que porta el símbolo gráfico del ave en vuelo, denominado "Almacén El Cóndor". ¿Sin ver la imagen que podríamos imaginar qué se distribuye en este almacén? Podría ser una pregunta interesante previa a la revisión de la imagen y de la siguiente descripción. Este almacén es una tienda de artículos producidos en plásticos, entre ellos se encuentran pisos, paredes, pegamentos y elementos sintéticos para instalar pisos a base de plásticos. Ahora bien, dando paso a resolver la inquietud que genera cada cacería, este no fue la excepción. Se dialogó con los empleados del almacén para saber si tenían claridad del porqué del nombre, y la escogencia de tal animal y no otro. Frente a lo cual, la respuesta de uno de los empleados fue: "El dueño del almacén tiene una gran admiración por esta ave" (Anónimo, 2019); además justificó que se debía a la cercanía de la especie con la cuidad. Esas fueron unas de las razones que condujeron a identificar el negocio con el cóndor de Los Andes. 


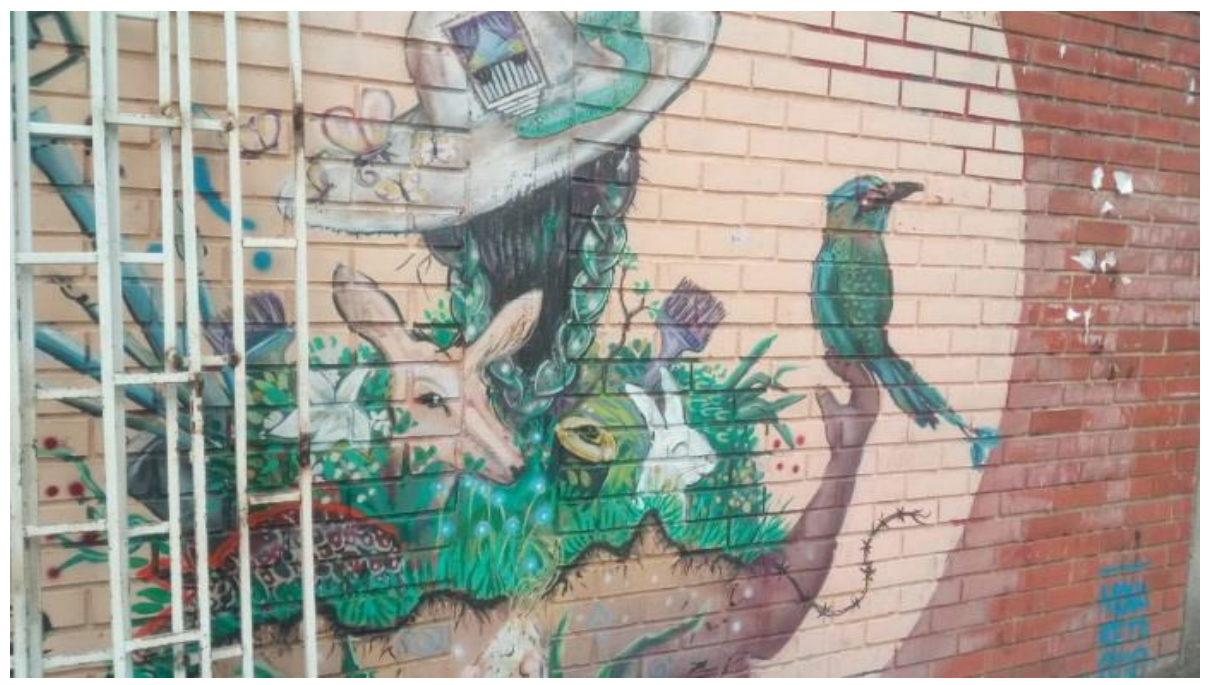

Figura 13. Mujer campesina en zona comercial. (Fuente: Luis Eduardo Barragán, 2019).

Se logró registrar el uso de la imagen del ratón (Mus musculus), que bien es un generador de rechazo más que de aceptación en la ciudad, se ha convertido en un símbolo alrededor del concepto de plaga, lo que ha permitido al comercio sin mayor esfuerzo publicitar dinámicas relacionadas con la exterminación de plagas a partir de la imagen del ratón. Este animalito se encontró en la fachada de una empresa de fumigación, y tal como lo sustentó su propietario, la especie está allí por la facilidad interpretativa y comunicativa en relación al servicio ofertado, no podría tener otro sentido, ya hace parte del imaginario de los fumigadores o exterminadores de plagas. Sin duda lo acompañan la cucaracha (Periplaneta americana), el comején (Isoptera), la hormiga (Formicidae), el grillo (Orthoptera, Gryllidae), la pulga (Siphonaptera) y la araña (Arachnida). Estos acompañan a la ciudad en su expansión y no son especies desconocidas, y por el rechazo que generan han sido utilizadas en las fachadas de los almacenes de fumigación, como lo veremos en la fotografía a la que corresponde este análisis.

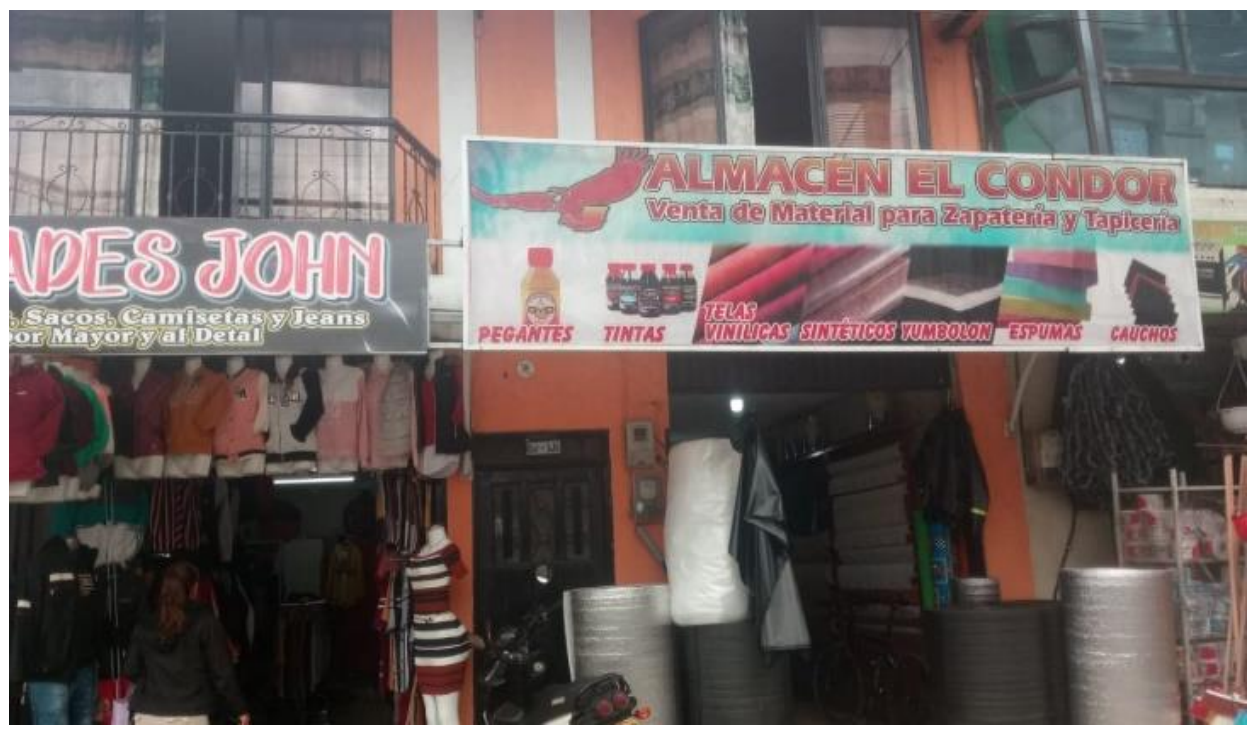

Figura 14. Cóndor nombrando a una tienda en la zona comercial del barrio La Esmeralda. (Fuente: Luis Eduardo Barragán, 2019). 


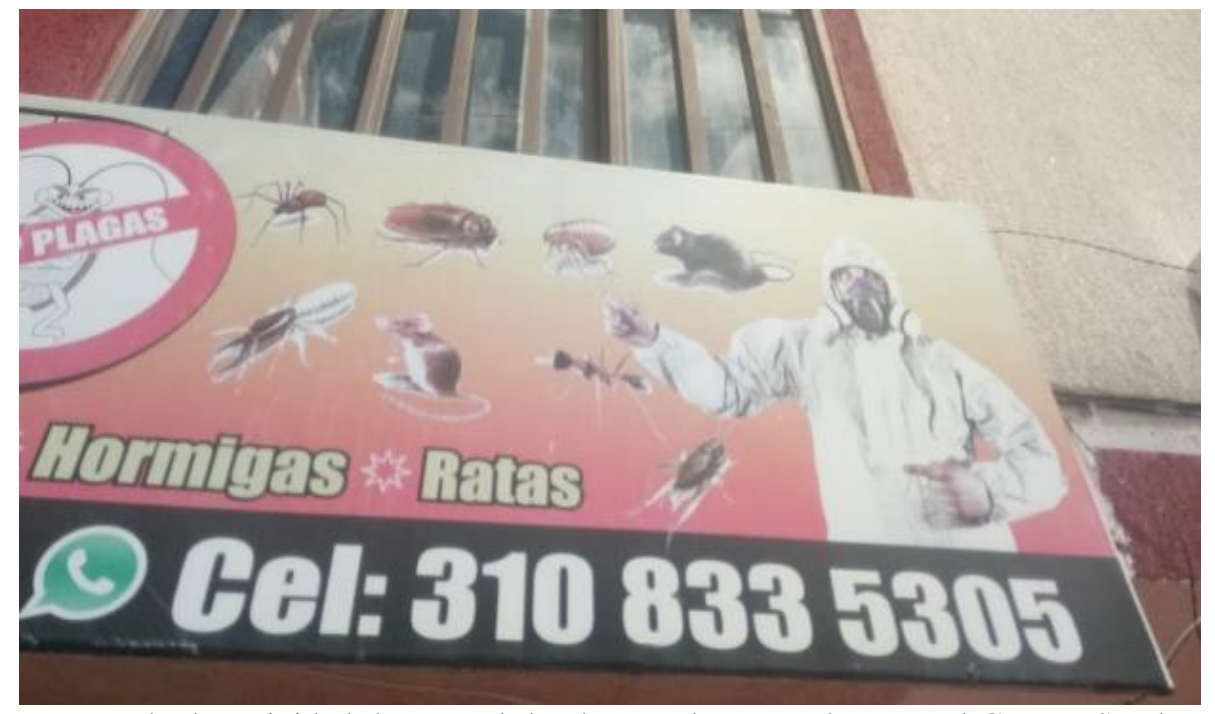

Figura 15. Propaganda de actividad de control de plagas urbanas en la zona El Centro. Se observan diferentes especies consideradas dañinas (Fuente: Luis Eduardo Barragán, 2019).

Que podríamos decir del mejor amigo del ser humano, la zoosemiótica lo presenta como uno de los animales que trasmite una serie de señales que están en uno de los niveles más altos de antropomorfización (Rozo, 2011). Existe un modismo que afirma con relación a esta especie: "Mi perro es tan inteligente que lo único que le falta es hablar". Palabra remplazada por las señales, por la propia zoosemiótica de este animal tan cotidiano en las familias como en las calles. Sus miradas, movimientos y aullidos han sido audazmente utilizados para fines publicitarios, tal como lo veremos a continuación. Vista desde la Semiótica, la publicidad consiste en la tarea de "crear un mundo con un lugar privilegiado para un producto" (Marafioti, 1995, p. 69).

El perro (Canis familiaris) juega un papel fundamental en las campañas publicitarias no solo de almacenes especializados para las mascotas, sino que en la cotidianidad de la ciudad se puede observar la introducción de esta especie en especial en los anuncios de ventas de apartamentos o en general en proyectos inmobiliarios, induciendo al imaginario de familia, como se puede ver en las fotos recolectadas. Para este estudio de caso se tomaron únicamente dos imágenes de las que pueden llegar a existir en la ciudad de Popayán, en tiendas de mascotas, almacenes de comida para animales o en vallas publicitarias que venden la idea de la familia idónea, que por supuesto no puede ser sin un perro y de preferencia de color amarillo. Responder al porqué de que los perros elegidos para este tipo de publicidad en especial sean perros de color amarillos entre ellos el Golden Retriever y el Labrador, podría responderse en el sentido de la búsqueda de apariencia de la familia blanqueada, netas adaptaciones extranjeras, fuera de contexto. Estas razas de color amarillo son de las dos razas más utilizadas en estes anuncios, se podría suponer dando una segunda respuesta, a que hace parte de la táctica publicitaria de los criadores de estas especies o se le podría sumar que estas especies, por ser unas de las más aptas por su conducta poco agresiva, sean las más apropiadas para una familia urbana.

Según Morris (1967), un animal es $100 \%$ atractivo cuando: 1) tiene pelaje; 2) tiene contornos redondeados; 3) tiene una cara plana; 4) tiene expresiones faciales; 5) puede manipular objetos pequeños; y 6) puede mantenerse erguido de vez en cuando. Es decir, cuando se puede antropomorfizarlo. Esta es la primera ley de la atracción animal: "La popularidad del animal varía en proporción directa al número de aspectos antropomórficos respectivos". Esta observación se aplica especialmente en el caso de las especies más cercanas al hombre (proximidad biológica en el caso de los mamíferos; análoga, en el caso de los insectos sociales). En este sentido, los perros y otros mamíferos (gatos, conejos, monos, etc.) que pueden ser antropomorfizados son completamente aceptados por el público en general. Según Morris, la elección del perro como símbolo de ternura y gentileza (características infantiles) puede ser determinada por la cultura, pero las razones para la elección reflejan un mecanismo biológico más profundo. 


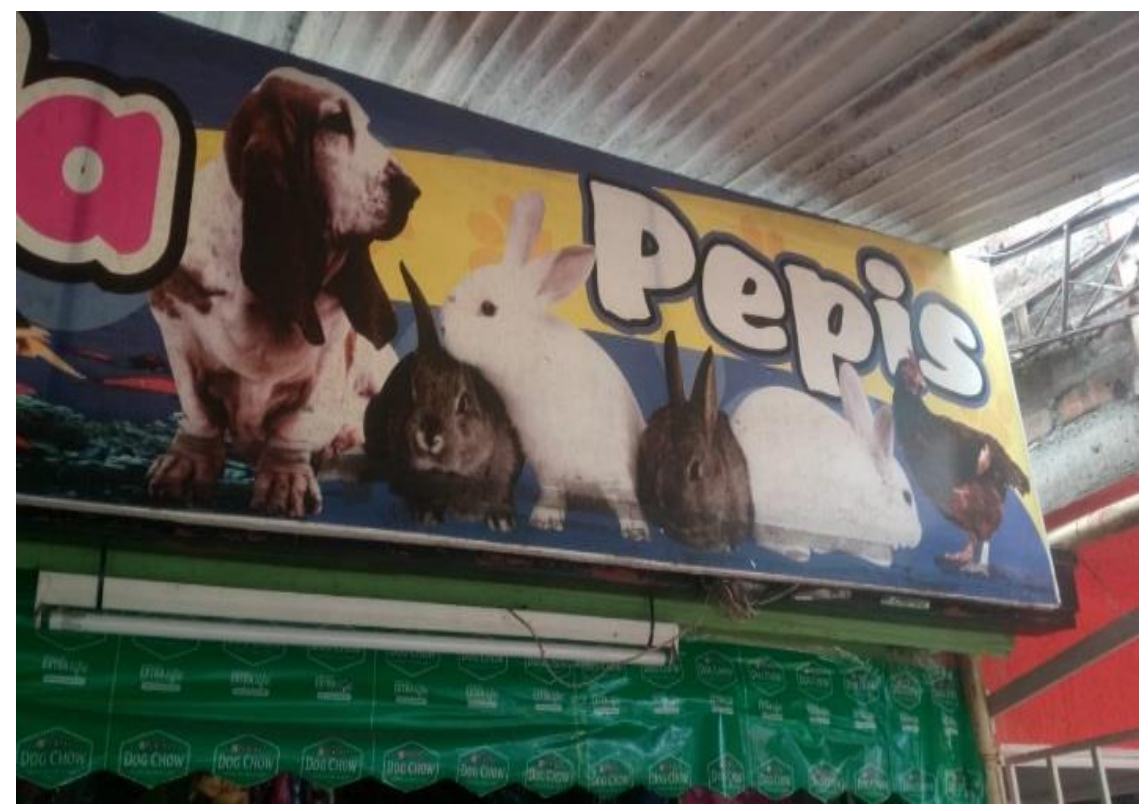

Figura 16. Almacén de productos para mascotas. (Fuente: Luis Eduardo Barragán, 2019).

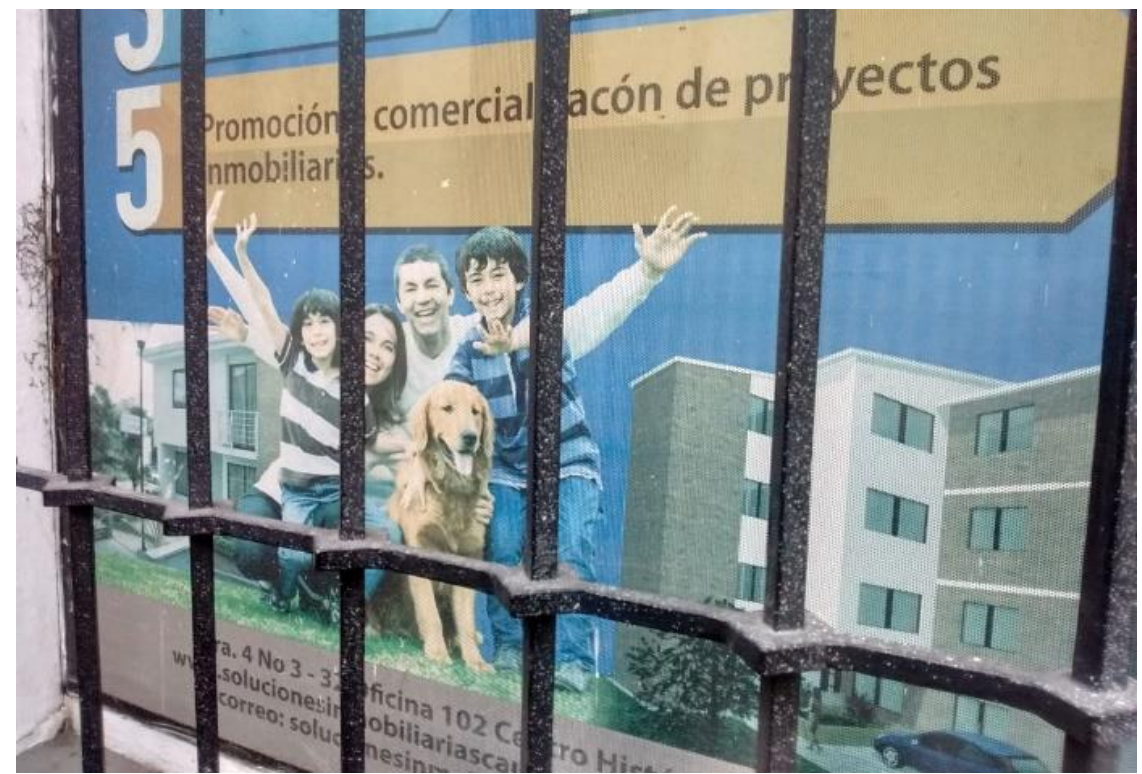

Figura 17. Afiche de venta de apartamentos en la zona El Centro. (Fuente: Luis Eduardo Barragán, 2019).

Una de las especies emblemáticas del Departamento del Cauca en el ecosistema paramo es el oso de anteojos (Tremarctos ornatus), animal que pudimos "cazar" en el barrio El Modelo, ubicado en una zona de venta de repuestos para vehículos y mecánica en general. Esta especie estaba acompañada del tigre (Panthera onca) y la danta de montaña (Tapirus pinchaque), animales que han sido ubicados en un mural al interior de uno de los vehículos emblema de Colombia, denominado chiva. Con solo ver la imagen de la chiva, se alude a las zonas rurales del país, en esta, el oso de anteojos aparece conduciendo una chiva y como pasajeros están los otros personajes. Al indagar a los más cercanos sobre este mural, ellos afirman que el trabajo se desarrolló de manera externa a ellos, por un grupo de jóvenes que a sol y agua adelantaron la labor. El sentimiento que envuelve a los dueños del taller donde está el mural es de alegría, por tener una pieza de este tipo que comunica información sobre las especies de la región y que además embellece la fachada y atrae la clientela. 


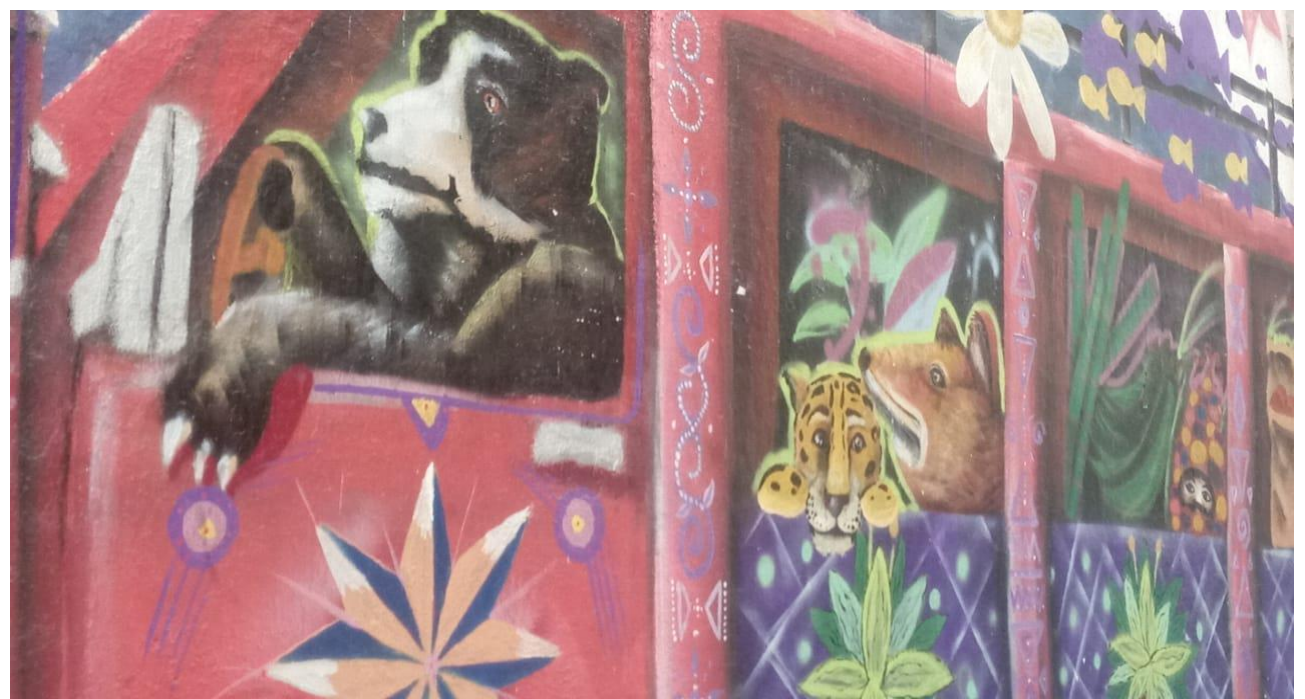

Figura 18. Oso de anteojos (Tremarctos ornatus), la danta (Tapirus pinchaque) y el jaguar (Panthera onca) trasladándose en un vehículo llamado chiva en el barrio Modelo. (Fuente: Luis Eduardo Barragán, 2019).

Por otra parte, la Facultad de Ciencias Humanas y Sociales de la Universidad del Cauca ha pasado por una lucha bastante ardua en cuanto a la apropiación de estos espacios. Teniendo en cuenta que es una pieza arquitectónica colonial en constante reparación y conservación, ha pasado a ser un lugar plano, vacío y sin color, todo por el cumplimiento de la normatividad en relación a estos espacios patrimoniales. Los estudiantes, en sus múltiples luchas por la apropiación del espacio universitario, el territorio y la territorialidad que representa estar constantemente en un lugar, avanzan en el paro nacional de la universidad pública desde hace un año. Una manera de apropiarse de las paredes de la universidad es la expresión pictórica de murales que han llenado de color, de sentido y de alegría la facultad, pasando de ser un lugar frio lúgubre a ser un lugar en contexto de las ciencias humanas y sociales. Una de las imágenes capturadas es la de un burro o asno (Equus asinus) cargado de múltiples artefactos y productos propios del campo, acompañado por un campesino que arrea el burro en el camino hacia la ciudad. Un ejercicio de proveer a esa ciudadanía del sabor y el saber de la cultura campesina, que caracteriza el territorio caucano y el país.

La imagen del burro es muy significativa, ya que no solo alude a los usos y costumbres de alrededor de la especie, sino que permite afianzar ese origen que enorgullece las gentes del campo inmersas en la ciudad. En la selva de cemento, si bien el burro no es un animal endémico de Colombia, ha sabido ganarse su papel en la memoria de este pueblo. Estos murales se han convertido en símbolo más allá de la imagen dado que representan el cumplimiento de las garantías que se lograron como resultado del paro nacional universitario en Colombia. Es también un símbolo del trabajo colectivo, de la lucha universitaria por la defensa de la educación pública, es un símbolo de perseverancia más allá de la imagen.

Las serpientes han jugado un papel simbólico representativo en la historia de la humanidad. Aún concebimos estas especies como algo tenebroso, generador de rechazo y símbolo de peligrosidad (Vizotto, 2003). En el marco de las manifestaciones aún activas en Colombia para el cierre de este estudio de caso, se presenta una actividad al interior de la Universidad del Cauca en la Facultad de Ciencias Humanas y Sociales, donde se presentó una convocatoria a partir de la imagen prediseñada de un cascabel (Crotalus sp.). Afiche que convoca al taller de creación de máscaras antigases, una imagen nada fuera de contexto: nada más peligroso que un grupo de policías armados de gases lacrimógenos atentando contra la población civil, con una letalidad y peligrosidad tal como la de un cascabel.

Imágenes como la de la serpiente fácilmente trasmiten información que logra con un nivel de eficacia captar la atención de los observadores. Particularmente, el diseño, la temática, el sentido y la razón de ser de este afiche permiten anclar en la memoria de un grupo de estudiantes un acontecer que demuestra en su significado, así como las condiciones, el sentir, el pensar y el actuar frente a la opresión de un gobierno que no se conduele con el estudiantado. 


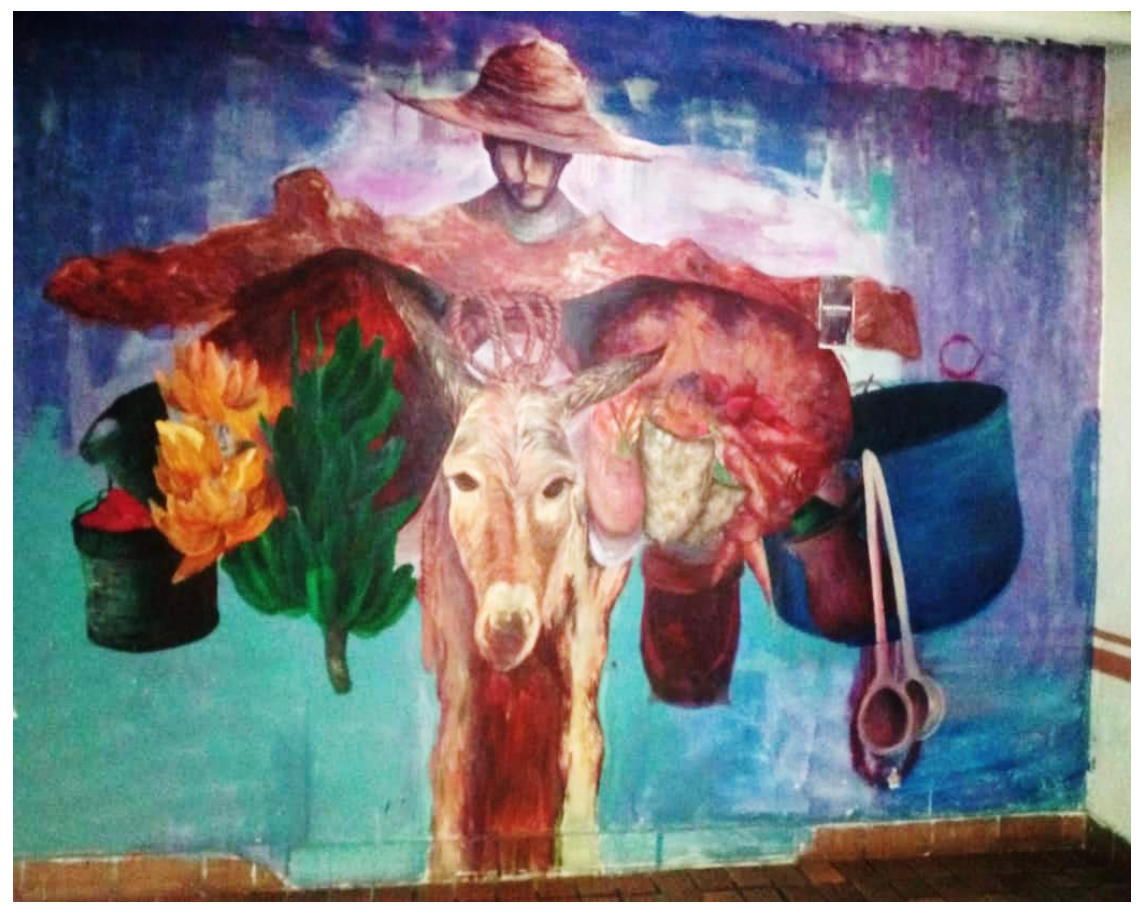

Figura 19. El campesino y el burro (Equus asinus). Mural en la Facultad de Humanidades de la Universidad del Cauca. Colombia. (Fuente: Luis Eduardo Barragán, 2019).

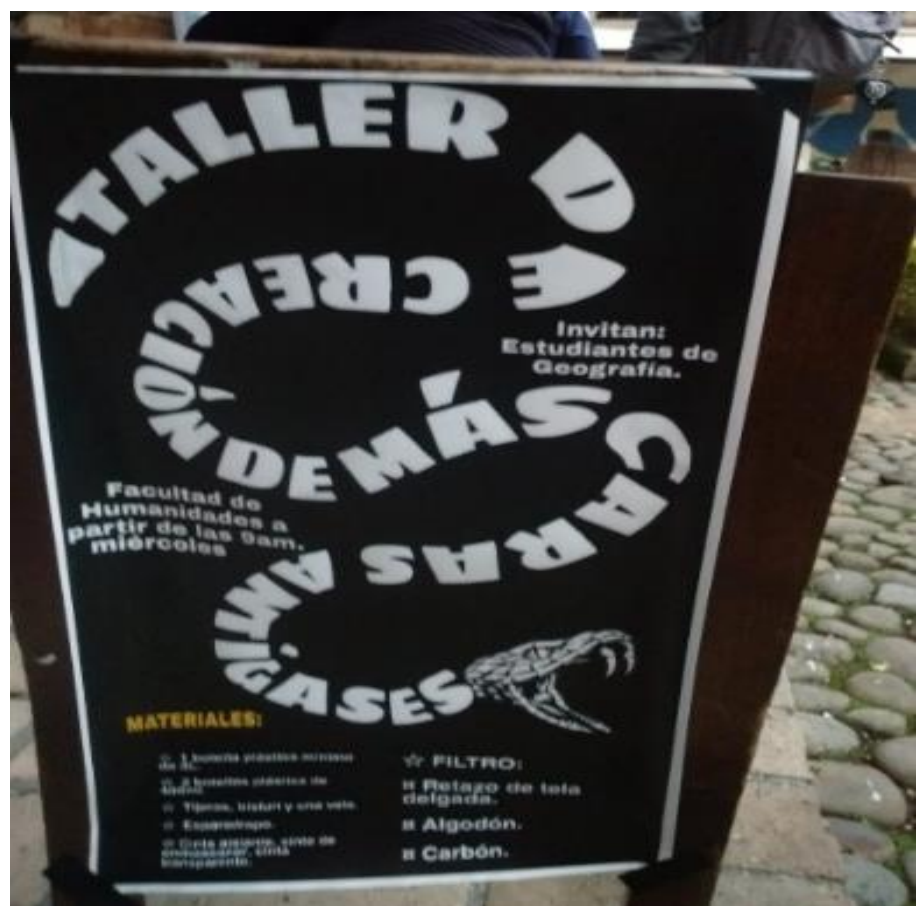

Figura 20. Cascabel estilizado en un afiche de un taller en la Universidad del Cauca. (Fuente: Luis Eduardo Barragán, 2019).

El ultimo resultado y discusión, pero no menos importante se denomina "el nido de la arara", Hostal la Araracura, posada para migrantes del mundo. El nido de la arara o guacamaya como posada de migrantes del mundo es un concepto adoptado por los propietarios de un hostal, dado que el abuelo de la familia, del propietario del hostal, presenta este lugar como un nido, donde los turistas son aves que migran por el mundo y que al llegar a la Araracuara pasan sus días en comodidad, para así dar paso a su migración por el mundo. Esta cacería urbana es resultado de este zafarí, que he llevado al primer autor hasta la Araracuara, un hostal en el centro de la ciudad de Popayán, que presenta una decoración que vislumbra al entrar en el nido. Este hostal en sus paredes ha dejado ver la hermosura del hogar de la guacamaya o arara (Ara chloropterus). Entrar a este lugar para el contexto colombiano 
es como trasladarse en el imaginario al pie de monte amazónico, la presencia de murales etnozoológicos dejan a la vista el tucán (Ramphastidae), la guacamaya (A. chloropterus) y a esto se le suma una composición de imágenes paisajísticas geomorfológicas que dan claridad de las condiciones del ecosistema de selva húmeda tropical.

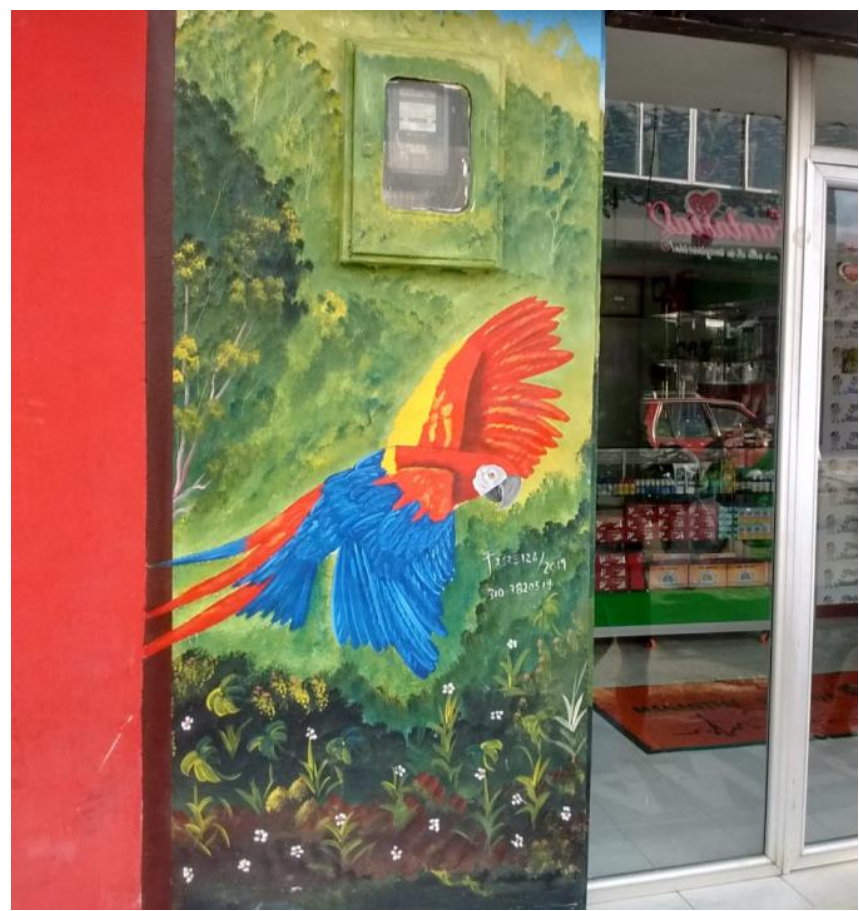

Figura 21. Guacamaya (Ara chloropterus) en la portada de un almacén naturista en la zona Centro de FlorenciaCaquetá. (Fuente: Luis Eduardo Barragán, 2019).

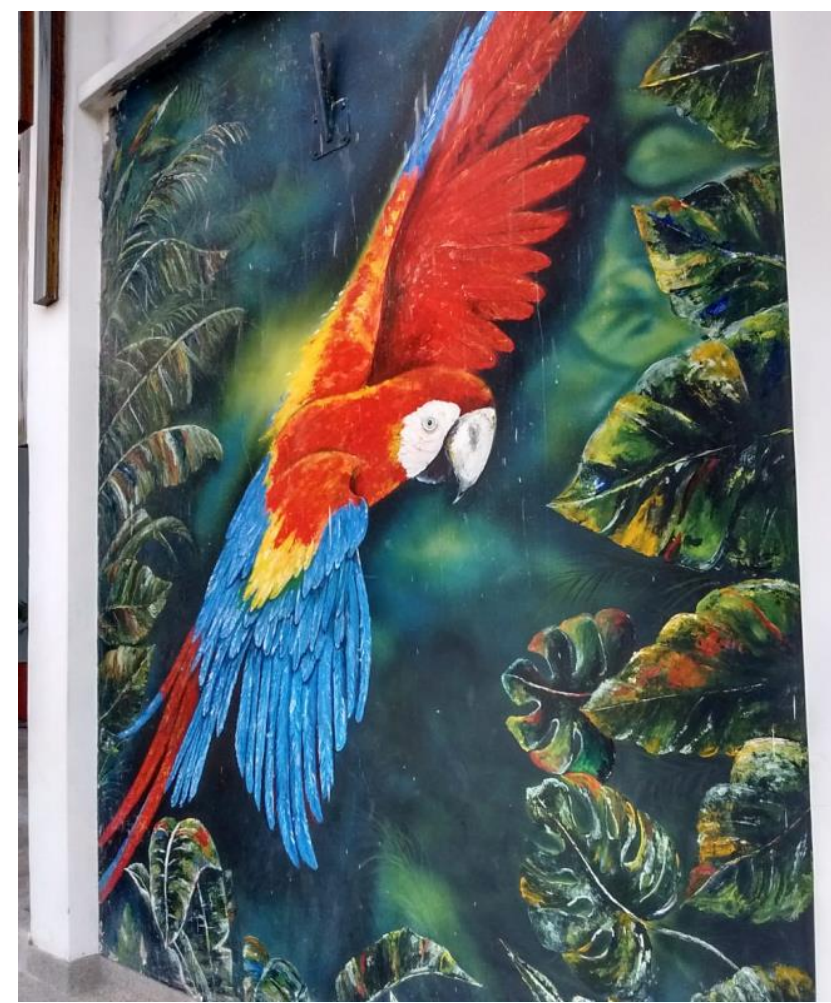

Figura 22. Dibujo de una guacamaya (Ara chloropterus) en el Hostal en El Centro de Florencia-Caquetá. (Fuente: Luis Eduardo Barragán, 2019).

Sin duda, se transmiten emociones a través de estas paredes, colores y formas, si bien el artista que desarrolla estas piezas llegó como parte de su migración por el mundo, al igual que otros, es un migrante que ha logrado arraigarse al lugar por medio de estas acciones artísticas. Este simbolismo a 
partir de la guacamaya ha estado en el imaginario de los colombianos por diversas razones, una de las más evidentes podría ser el color del ave que viene siendo el mismo color de la bandera de Colombia. La guacamaya bandera es por definición un ave emblemática de Colombia y, en especial, del sur del país en el pie de monte amazónico. Aspecto que causó tal grado de interés en esta investigación, que condujo al investigador a profundizar sobre la utilización de esta imagen en el contexto del pie de monte amazónico, que para Colombia vendría siendo el Departamento del Caquetá, especialmente su capital, la ciudad de Florencia.

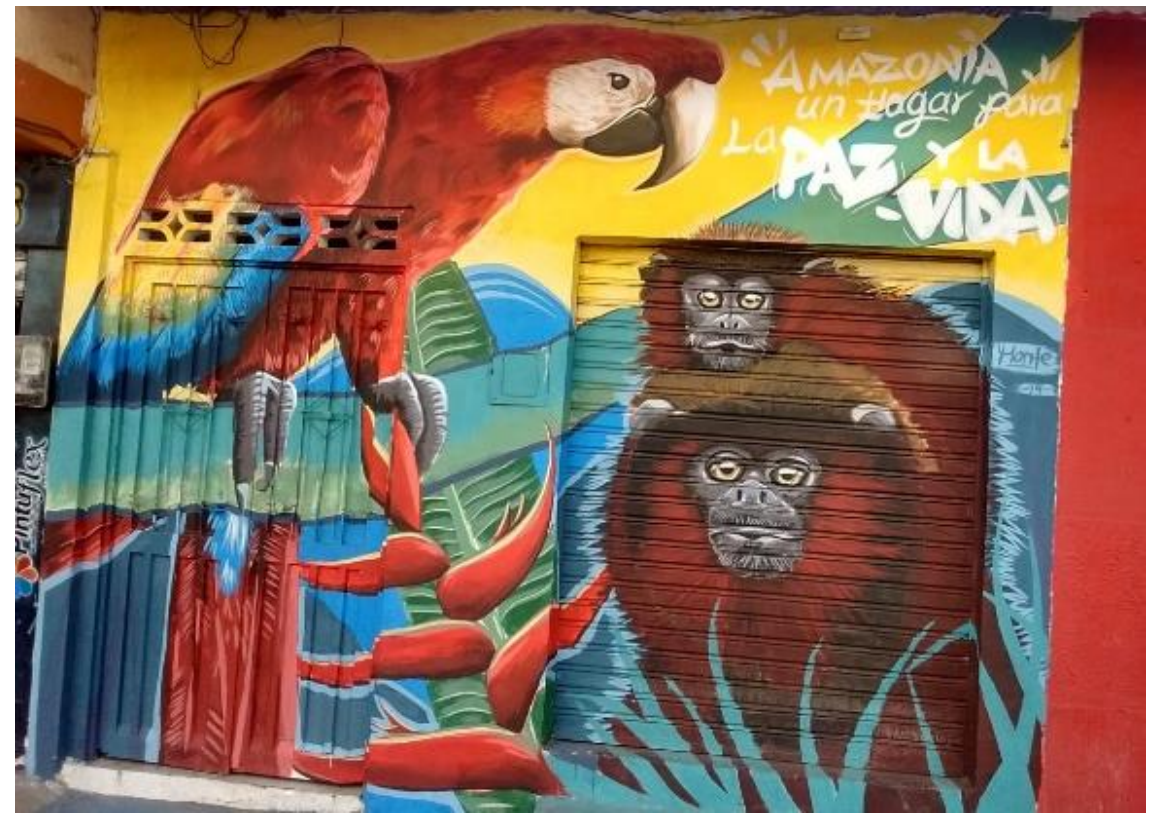

Figura 23. Almacén de pinturas en la zona Centro de Florencia-Caquetá. (Fuente: Luis Eduardo Barragán, 2019).

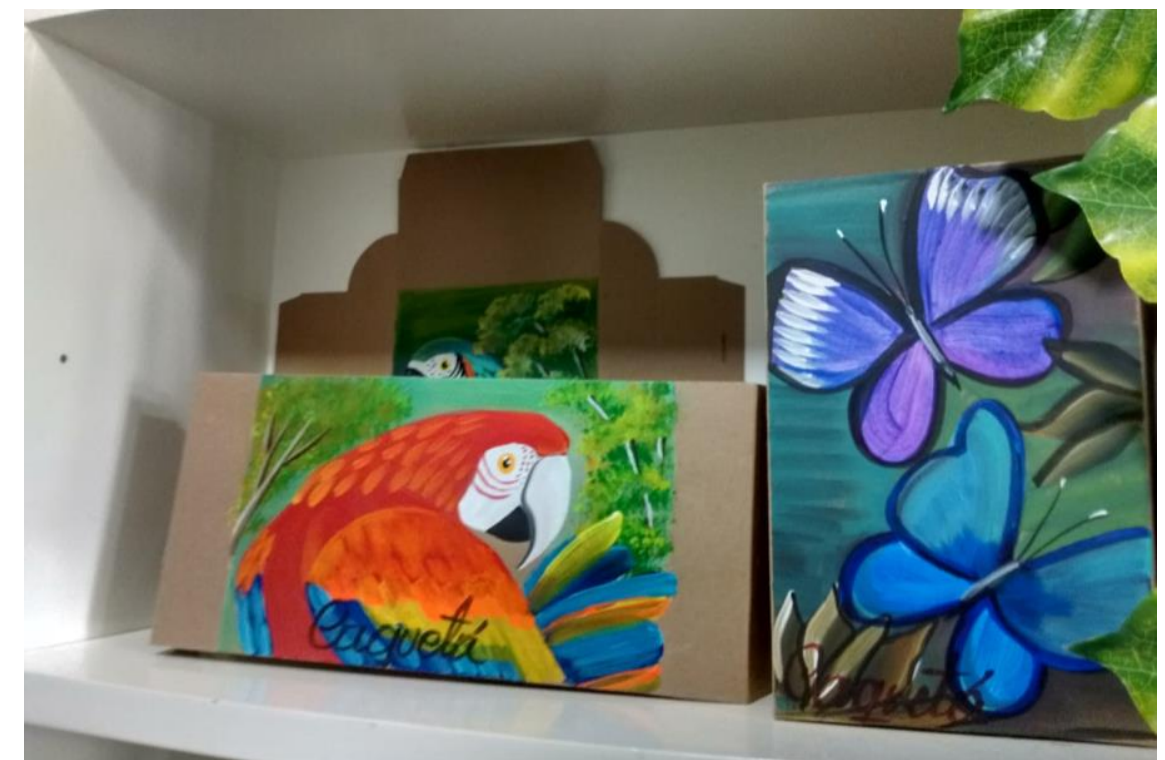

Figura 24. Cuadros en venta en un almacén artesanal en la zona Centro de Florencia-Caquetá. (Fuente: Luis Eduardo Barragán, 2019).

Revisión que gira en torno a resolver si al igual que lo que ocurre en la ciudad de Popayán, con sus especies faunísticas insignia poco empleadas en la publicidad local, revisando por medio de esta observación participante si este fenómeno con relación a esta especie en contexto le ocurre lo mismo, es decir, si goza de ese alto grado de desconocimiento e implementación en las imágenes publicitadas de esta ciudad. Para ello, se hizo un viaje a la ciudad de Florencia-Caquetá a 300 kilómetros de la ciudad de Popayán, tras la búsqueda de símbolos convencionales etnozoológicos que permitieran resolver la duda que generó el déficit de imágenes de especies insignia del Cauca en la 
ciudad de Popayán. Al llegar a Florencia, se adelantó un recorrido por la ciudad de menos de una hora y en un tramo de menos de cuatro manzanas alrededor del centro de la ciudad había cinco murales con la guacamaya como símbolo acompañado de mensajes como "Amazonía un lugar para la paz y la vida". Así, se evidencia que este es un elemento que predomina en la ciudad como representación gráfica, actuando como un estímulo que atrae y direcciona hacia un acercamiento con los locales comerciales. Pues si bien hace parte de una estrategia muy bien pensada para generar un estímulo comercial, que establece una comunicación previa, "que intenta dar a entender lo que se supone que otro quiere comunicar" (Ong, 1997). Presentado de esta forma, el uso que da la ciudad a los recursos naturales, al signo representativo de la fauna local como estrategia comercial más allá de la imagen. Esto se puede entender como un discurso local sobre el medio natural, que demuestra las relaciones con la naturaleza.

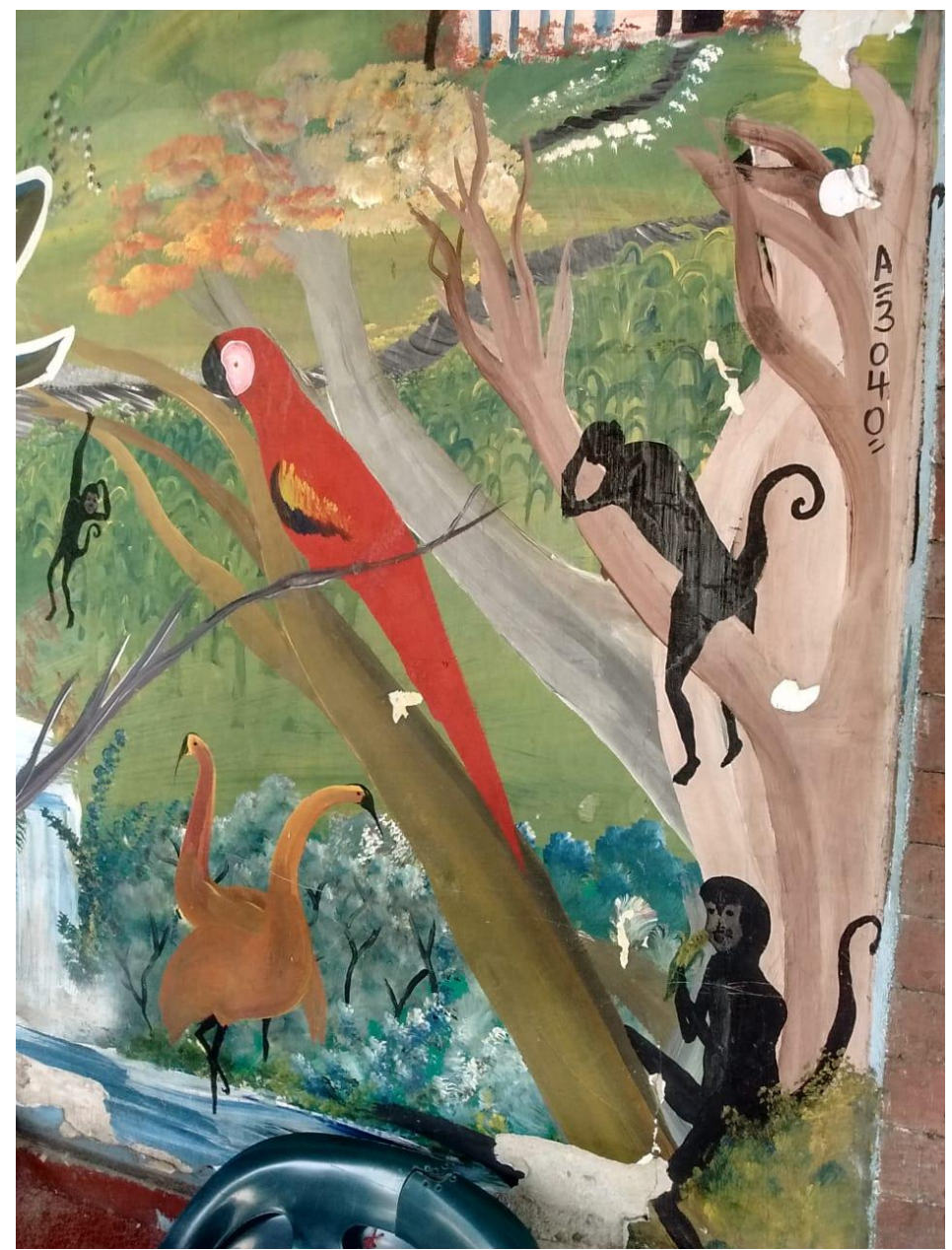

Figura 25. Almacén de distribución de maíz en zona comercial de Florencia-Caquetá. (Fuente: Luis Eduardo Barragán, 2019).

\section{CONCLUSIONES}

Los elementos perceptuales a los que accedemos a través de los análisis etnozoológicos en ecosistemas urbanos y la utilización de la imagen faunística en sus procesos comunicativos locales, permiten abrir una discusión hacia la ejecución y aplicación de una educación ambiental a nivel local y mundial. No serían pocos los avances logrados a partir de aproximaciones de este tipo dada la bondad del signo en cuanto a la comunicación. Vale mencionar que la conciencia ambiental frente a los fenómenos antropogénicos que observamos en el ecosistema tierra, o el planeta agua, son cada vez más evidentes.

Podemos observar también cada vez más como se naturalizan los servicios ecosistémicos por medio del modelo de consumo, apartando la intrínseca relación cultura-naturaleza que hacía parte de nuestra memoria pre-capitalista. 
Consecuentemente, queda una ardua tarea para aquellos que se atrevan a asumir el papel de diseñar estrategias que complementen los métodos pedagógicos tradicionales de aprendizaje, bajo los que estamos siendo influenciados y coaccionados. La educación ambiental viene tomando una forma cada vez más densa en la medida en que avanza el deterioro del planeta, al ritmo acelerado del modelo de consumo. Puntualmente, en las escuelas, el enfoque en educación ambiental está relegado por temas complementarios y no contenidos principales en la formación de nuestros relevos. Situación que favorece el desconocimiento y la pérdida de identidad. En estas circunstancias, la educación ambiental no permea de manera satisfactoria la educación primaria y secundaria de nuestros pueblos. Actualmente en Colombia se ha diseñado nuevas políticas de educación ambiental que aportan nuevos elementos y que sería importante tener en cuenta. Igualmente, la Política Nacional para la Gestión Integral de la Biodiversidad y sus Servicios Ecosistémicos aporta nuevos elementos a la educación ambiental. Todo este proceso educativo debe quedarse lo más posiblemente entrañado en los planes gubernamentales para abarcar a todos los ciudadanos.

La hipótesis que se plantea en el contexto de cualquier ciudad puede llegar a ser aplicada con la implementación de talleres urbanos fuera del aula. Los cuales permitan elevar los niveles perceptuales de los participantes y reconstruirlos a través de una discusión gráfica. Estrategia que se puede complementar con una actividad viable como puede ser un recorrido de observación, direccionado por el docente de múltiples maneras y enfocarlas a los planes de estudio de su institución o colectivo, más aun frente a las tecnologías de la información y la comunicación, se puede decir que brindan la posibilidad de innovar en las acciones pedagógicas con enfoques de tipo etnozoológico, brindar al urbanista un proceso metodológico que accede a las líneas de lo cognitivo, de un aprendizaje en contexto. Es incoherente hablar de defensa del territorio, de biodiversidad, de conservación y más una de especies en vía de extensión cuando ni siquiera se conocen, se perciben o se interpretan el hábitat al cual pertenecemos.

\section{AGRADECIMIENTOS}

LEBL agradece a la divinidad por la familia y por permitirle visualizar con claridad el camino que desea en armonía recorrer, al igual que a los múltiples mensajes perceptibles que le acompañan en el transitar del diario vivir. "Gracias ese Espíritu maravilloso Divino que rodea mi entorno y despeja mi camino."

Sin duda agradecemos al Departamento de Geografía de la Universidad del Cauca, a la profesora Carolina Castrillón Ojeda por confiar en este proceso, al Doctorado en Etnobiología y Estudios Bioculturales, en dirección de la doctora Olga Lucia Sanabria y a sus colaboradores por permitir hacer parte de estos cursos tan maravillosos.

\section{BIBLIOGRAFÍA}

Alcaldía Municipal de Popayán. Popayán. Disponible en 〈http://popayan.gov.co/ciudadanos/popayan〉. Acesado en: 28 abr. 2020.

Alvarado Corredor, J. G.; Gualteros Blanco, E. F. Formulación de un proyecto ciudadano de educación ambiental "PROCEDA" para el sector cuesta de Chapinero Ibagué - Tolima. 2016. 145 f. Tesis de Especialización en Educación y Gestión Ambiental, Universidad Distrital Francisco José de Caldas, Bogotá, D.C., 2016.

Araújo, H. F. P.; Lucena, R. F. P.; Mourão, J. S. Prenúncio de chuvas pelas aves na percepção de moradores de comunidades rurais no município de Soledade-PB, Brasil. Interciencia, v. 30, n. 12, p. 764-769, 2005.

Buckley, R.; Araújo, G. 1997. Green advertising by tourism operators on Australia's gold coast. Ambio, v. 26, n. 3, p. 190-191, 1997.

Cajiao, F. La concertación de la educación en Colombia. Revista Iberoamericana de Educación, v. 34, p. 31-47, 2004.

Carson, R. Silent spring. Boston: Houghton Mifflin, 1962.

Chalate-Molina, H. et al. Características del sistema de producción bovinos de doble propósito en el estado de Morelos, México. Zootecnia Tropical, v. 28, n. 3, p. 329-339, 2010.

Clapp, J.; Newell, P.; Brent, Z. W. The global political economy of climate change, agriculture and food systems. The Journal of Peasant Studies, v. 45, n. 1, p. 80-88, 2018.

Costa Neto, E. M. O uso de estímulos-sinais entomomorfos na publicidade. Bioikos, v. 14, n. 1, p. 49-53, 2000.

Costa Neto, E. "Caçando" bichos na selva urbana: um estudo de caso na cidade de Feira de Santana, Bahia, Brasil. Bioikos, v. 18, n. 2, p. 21-25, 2004. 
Cotos, A. G.; Ayala, R. B.; Valencia, J. A. Organizaciones de población desplazada en la construcción de presentes y futuros dignos. Estudios Políticos, n. 37, p. 73-94, 2010.

Delariva, R. L. y Agostinho, A. A. Introdução de espécies: uma síntese comentada. Acta Scientiarum, v. 21, n. 2, p. 255-262, 1999.

Futterleib, L. E. L.; Azevedo, J. F. F. A Utilização de Animais na Publicidade e Propaganda. In: SALÃO DE

INICIAÇÃO CIENTÍFICA, 14 ., $2013 . \quad$ Anais... $\quad$ Disponible
<http://editora.pucrs.br/anais/SIC/XIV/XIV/627.pdf>. Accesado en 28 abr. 2020.

Galvagne-Loss, A. T.; Costa Neto, E. M. y Flores, F. M. Ornitoáugures no povoado de Pedra Branca, Santa Teresinha, Estado da Bahia, Nordeste do Brasil. Etnobiología, v. 11, n. 3, p. 45-53, 2013.

Halliday, M. El lenguaje como semiótica social. México: Fondo Cultural de Economía, 1978.

Hernández, A. Nuevos tiempos, necesidad de un cambio en la relación persona-sociedad-naturaleza. Trama, v. 6, n. 2: 73-87, 2017.

Herrera, G. C. Naturaleza, sociedad e historia en América Latina. Política y Sociedad, n. 17, p. 41-58, 1994. Marafioti, R. Los significantes del consumo. Buenos Aires: Editorial Biblos, 1995.

Marques, J. G. W. O sinal das aves. Uma tipologia sugestiva para uma etnoecologia com bases semióticas. In: Albuquerque, U. P. de; Alves, A. G. C.; Lins e Silva, A. C. B.; Silva, V. A. de (orgs.). Atualidades em Etnobiologia e Etnoecologia. Recife: Sociedade Brasileira de Etnobiologia e Etnoecologia, 2002. p. 87-96.

Marques, J. G. W.; Andrade, C. T. S. Semiótica publicitária zoofílica. 1- peixe é bom para "vender o peixe". In: SIMPÓSIO BRASILEIRO DE ETNOBIOLOGIA E ETNOECOLOGIA, 2, 1998, São Carlos. Resumos... São Carlos: UFSCar, 1998. p. 89.

Morris, C. W. The concept of the symbol. Journal of Philosophy, v. 24, p. 253-262; 281-291, 1927.

Morris, C. W. Peirce, Mead and pragmatism. Philosophical Review, v. 47, p. 109-127, 1938.

Morris, C. W. Fundamentos de la teoría de los signos. Barcelona: Paidós, 1971.

Morris, D. O macaco nu. São Paulo: Círculo do Livro, 1967.

Municipio de Popayán. Plan de ordenamiento territorial. Documento técnico, Componente ambiental, 2000.

Myers, N.; Mittermeier, R.A.; Mittermeier, C.G.; da Fonseca, G.A.B.; Kent, J. Biodiversity hotspots for conservation priorities. Nature, v. 403, p. 853-858, 2000.

Niño, V. Semiótica y lingüística: fundamentos. Bogotá: Eco Edición, 2013.

Ong, W. J. Oralidad y escritura: tecnologías de la palabra. 2. ed. México: Fondo de Cultura Económica, México, 1997.

Rahman, A. y Fals Borda, O. La situación actual y las perspectivas de la IAP en el mundo. En: Salazar, M. C. (coord.). La investigación-acción participativa: inicios y desarrollos. Madrid: Ed. Popular, 1992. p. 205-230.

Rodríguez, J. P. La amenaza de las especies exóticas para la conservación de la biodiversidad suramericana.

INCI, v. 26, n. 10, p. 479-483, 2001.

Rozo, D. C. Tras el animal: dos persecuciones ontológicas. Revista CS, n. 7, p., 377-408, 2011.

Saussure, F. Les sources manuscrites du "cours de linguistique generale" de Ferdinand de Saussure. Genebra: Droz, 1969

Sebeok, T. A.; Hayes, A.; Bateson, M. C. Semiótica aplicada. Madrid: Nueva Visión, 1978.

Soulé, M. E. Mente na biosfera; mente da biosfera. In: Wilson, E. O. (ed.). Biodiversidade. Rio de Janeiro: Nova fronteira. 1997. p. 593-598

Souza, V. S.; Zoboli, F.; Silva, R. I.; Bomfim, E. S. M. Análise semiótica da marca Puma: da construção do argumento à incorporação dos signos. Corpus et Scientia, v. 11, n. 1, p. 1-12, 2015.

Ulloa, A. Rostros culturales de la fauna: las relaciones entre los humanos y los animales en el contexto colombiano. Bogotá: Instituto Colombiano de Antropología e Historia, 2002.

Vargas Garzón, B.; Molina Prieto, L. F. Árboles para Popayán: especies que fortalecen la estructura ecológica principal. Revista nodo, v. 2, n. 4, p. 55-69, 2008.

Vidales, C. La relación entre la semiótica y los estudios de la comunicación: un diálogo por construir.

Comunicación y Sociedad, n. 11, p. 37-71, 2009.

Vilá, M. et al. Impactos ecológicos de las invasiones de plantas y vertebrados terrestres en Europa. Ecosistemas, v. 15, n. 2, p. 13-23, 2008.

Vizotto, L. D. Serpentes: lendas, mitos, superstições e crendices São Paulo: Editora Plêiade 2003.

Zamora, H. Análisis biogeográfico de los macroinvertebrados acuáticos epicontinentales (MAE) en el Departamento del Cauca, Colombia. Unicauca Ciencia, v. 5, p. 11-30, 2000. 